University of Rhode Island

DigitalCommons@URI

Open Access Master's Theses

2014

\title{
A COMPARISON OF THE DEVELOPMENT OF THE LATERAL LINE CANAL PORES IN TWO SPECIES OF CICHLID FISHES WITH FUNCTIONALLY DISTINCT CANAL MORPHOLOGIES
}

Lauren E. Carter

University of Rhode Island, carterl@my.uri.edu

Follow this and additional works at: https://digitalcommons.uri.edu/theses

\section{Recommended Citation}

Carter, Lauren E., "A COMPARISON OF THE DEVELOPMENT OF THE LATERAL LINE CANAL PORES IN TWO SPECIES OF CICHLID FISHES WITH FUNCTIONALLY DISTINCT CANAL MORPHOLOGIES" (2014). Open Access Master's Theses. Paper 362.

https://digitalcommons.uri.edu/theses/362

This Thesis is brought to you for free and open access by DigitalCommons@URI. It has been accepted for inclusion in Open Access Master's Theses by an authorized administrator of DigitalCommons@URI. For more information, please contact digitalcommons-group@uri.edu. 
A COMPARISON OF THE DEVELOPMENT OF THE LATERAL LINE CANAL PORES IN TWO SPECIES OF CICHLID FISHES WITH FUNCTIONALLY DISTINCT CANAL MORPHOLOGIES

BY

LAUREN E. CARTER

A THESIS SUBMITTED IN PARTIAL FULFILLMENT OF THE

REQUIREMENTS FOR THE DEGREE OF

MASTER OF SCIENCE

IN

BIOLOGICAL AND ENVIRONMENTAL SCIENCES

UNIVERSITY OF RHODE ISLAND

2014 
MASTER OF SCIENCE

OF

LAUREN E. CARTER

APPROVED:

Thesis Committee:

Major Professor Jacqueline F Webb

Steven Irvine

David Bengtson

Nasser H. Zawia

DEAN OF THE GRADUATE SCHOOL

UNIVERSITY OF RHODE ISLAND

2014 


\begin{abstract}
The cranial lateral line system (LL) is composed of a series of bony, pored canals that are integrated within a conserved subset of dermatocranial bones. Neuromast receptor organs are located in the canals between positions of adjacent canal pores, which link the fluid within the canals to the fluid of the external environment. Among species the lateral line canals can be narrow, narrow with widened tubules, widened, branched, or reduced. The goal of this project was to examine ontogenetic trends in size and shape of canal pores within and between two cichlid species, Aulonocara stuartgranti (widened canals) and Tramitichromis sp. (narrow canals). Pore placement and size are thought to have functional implications for canal neuromast function, and therefore has implications on behavior. Thus, ontogenetic changes in pore number, size, and shape deserve study. Several hypotheses concerning ontogenetic trends in pore size, area, and inter-pore distance were tested using the pores of the supraorbital and mandibular canals. The data presented here are the first of their kind, showing ontogenetic trends of pore morphology from the larval stage (using histological analysis), through the juvenile and adult stages (using methylene blue stained and cleared and stained specimens). Results show differences in trends between species and within species among pore types (bony, epithelial) where bony pores are larger, in general, than epithelial pores and Aulonocara have larger pores than Tramitichromis. In most instances, similar trends are seen in larvae, juveniles, and young adults
\end{abstract}




\section{ACKNOWLEDGMENTS}

I would like to thank my major professor, Dr. Jacqueline Webb, for allowing me to complete my research in her lab and for supporting and guiding me along the way. She has taught me to keep moving forward even when things do not seem to be going your way and she has shown me that hard work and determination are the keys to success. I would like to thank my committee members, Dr. Steven Irvine and Dr. David Bengtson, for their advice and support through the process. I would also like to thank Dr. Nathan Bird for always being there for me in times of need. He was always willing to lend a helping hand, show me how to do a technique, or answer any of my million questions I always had. I am forever grateful for all you have taught me. I owe a lot of my success in this project to you.

I would like to thank Dr. Margot Schwalbe, Emily Becker, and Ashley Marranzino for their assistance and encouragement in the lab. They would make me laugh when I wanted to cry and made coming into lab everyday enjoyable. I would also like to thank the undergraduates, Chris Holland and Ben Sevey, for assistance with fish care. They made sure that the fish were happy and made my life a lot easier.

Lastly, I would like to thank my family and friends. Thanks to my family who have always told me to go for my dreams and never stop believing. I know they will continue to support me through thick and thin. Thanks to all of my friends, specifically Lindsay Stephenson and Bonnie Colantuono, for always being there and supporting me up until the end. I have the best family and friends in the world and would not be where I am today without their love and support. This work was funded by NSF Grant \# IOS 0843307 to JFW and NSF EPSCoR Cooperative Agreement EPS-1004057. 


\section{TABLE OF CONTENTS}

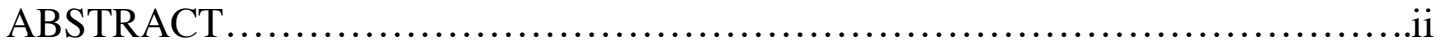

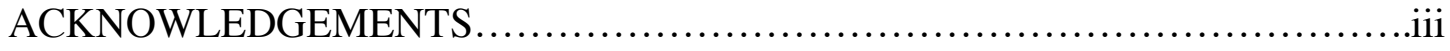

TABLE OF CONTENTS ..........................................................

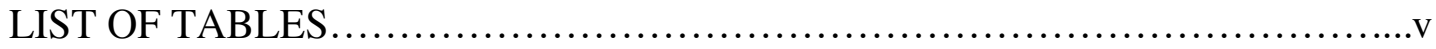

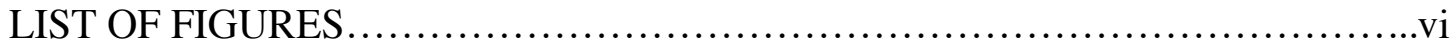

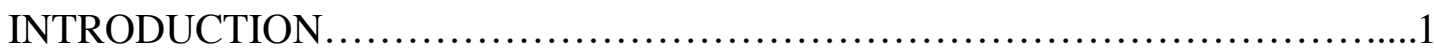

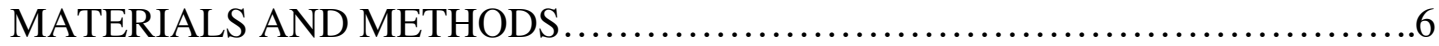

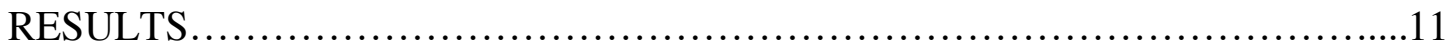

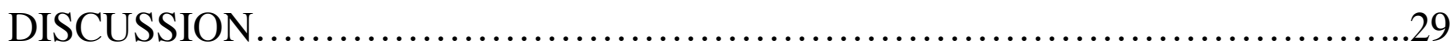

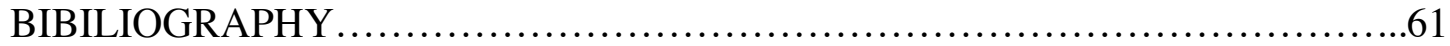




\section{LIST OF TABLES}

TABLE

PAGE

Table 1. Number of bony and epithelial pores (right+left, SO+MD combined) in larval and juvenile Aulonocara and Tramitichromis (8-59 mm SL, standard length)........................38

Table 2. Summary ANOVA statistics for pore parameters vs. fish length (mm SL) for Aulonocara $(A U)$ and Tramitichromis (TRA), using MD and SO data combined (COMB) and MD and SO data considered separately....

Table 3. Summary ANCOVA statistics for comparison of slopes between species (Aulonocara and Tramitichromis), for each pore parameter vs. fish length 43 


\section{LIST OF FIGURES}

FIGURE

PAGE

Figure 1. Schematic diagram of (A) a superficial and (B) a canal neuromast. 45

Figure 2. Drawing of skull of an adult convict cichlid (Amatitlania nigrofasciata) from a cleared and stained specimen showing the pored lateral line canals embedded in dermal bones. .46

Figure 3. Neuromast-centered canal morphogenesis and fusion of adjacent canal segments....

Figure 4. Five cranial lateral line canal morphologies found among fishes. 48

Figure 5. Graphical representation of six hypotheses tested in this study

Figure 6. Definition of measurements taken for quantitative analysis of the ontogeny of bony and epithelial pores in the MD canal (of Aulonocara, as an example). .50

Figure 7. Definition of measurements taken for quantitative analysis of the ontogeny of bony and epithelial pores in the SO canal (of Aulonocara, as an example).

Figure 8. Configuration of the A) supraorbital ( $\mathrm{SO}$ ) canal in the nasal and frontal bones, and the B) mandibular (MD) canal in the dentary and anguloarticular bones, indicating the location of the canal neuromasts and the canal pores located between neuromasts

Figure 9. Comparison of the ontogeny of bony and epithelial pore area in larger juveniles and adults in A) Tramitichromis and B) Aulonocara .53

Figure 10. Proliferation of epithelial pores in the supraorbital canal (SO) in Aulonocara and Tramitichromis 
Figure 11. Comparison of Tramitichromis and Aulonocara with respect to bony pore width and epithelial pore width in larvae, juveniles, and young adults using data from SO and MD canals combined. .55

Figure 12. Comparison of Tramitichromis and Aulonocara with respect to bony pore length and epithelial pore length using data from SO and MD canals combined.....56

Figure 13. Comparison of Tramitichromis and Aulonocara with respect to pore area. A) Bony pore area (data from $\mathrm{SO}+\mathrm{MD})$ of larvae and small juveniles (8-19.5 mm SL)

Figure 14. Comparison of distance between bony and epithelial pores in Tramitichromis and Aulonocara. A) Distance between bony pores (SO+MD) of larvae and small juveniles between species........................................... 58

Figure 15. CT reconstructions of the mandibular canal in adult Tramitichromis and

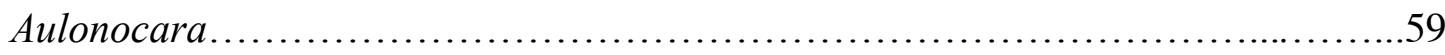

Figure 16. Schematic representation of overall statistical trends in four different morphological parameters (SO and MD data combined), in larvae and juveniles of Aulonocara and Tramitichromis. 


\section{INTRODUCTION}

The mechanosensory lateral line system is a primitive craniate sensory system that is found in all fishes and in larval and adult aquatic amphibians. It is used to detect hydrodynamic stimuli and is essential for survival in the aquatic environment. The lateral line system has been implicated in several behaviors including rheotaxis (Djikgraaf, 1962; Montgomery et al., 1997), prey detection (Kanter and Coombs, 2002; Montgomery and Coombs, 1998; Coombs et al., 2001; Schwalbe et al., 2012; Schwalbe et al., 2014), obstacle avoidance (Windsor et al., 2008) and courtship/spawning (Satou et al., 1994).

The lateral line system is composed of hair cell-based receptor organs called neuromasts (Coombs et al., 1988). There are two types of neuromasts: superficial neuromasts and canal neuromasts. Each neuromast is composed of sensory hair cells, non-sensory cells, and mantle cells. Each hair cell has one kinocilium and multiple, graded stereocilia. The position of the kinocilium relative to the stereocilia determines the axis of greatest physiological sensitivity of the hair cells (Kasumyan, 2003), thus defining hair cell orientation. The kinocilia and stereocilia of all hair cells in a neuromast are embedded in a gelatinous cupula that extends into the water and is deflected by water flows (Figure 1). The deflections stimulate the hair cells, which are transduced into electrical potentials that are transmitted to the hindbrain via the lateral line nerves (Windsor and McHenry, 2009).

Canal neuromasts are found within fluid-filled lateral line canals and are sensitive to water accelerations (Webb et al., 2014). Cranial canals in the head are embedded in a conserved subset of dermatocranial bones and found above the eye, below the eye, on the preoperculum, and on the lower jaw. For example, the supraorbital (SO) canal is located 
above the eye in the nasal and frontal bones, and the mandibular (MD) canal is located in the lower jaw in the dentary and anguloarticular bones (Webb, 1989b; Figure 2).

The development of the lateral line system is a prolonged process that begins during the embryonic stage and continues through the juvenile stages. It occurs in three phases (Webb, 1989a): 1) migration/elongation of placode-derived lateral line primordia and differentiation of neuromasts, 2) growth and proliferation of the neuromasts, and lastly 3) morphogenesis of lateral line canals with the enclosure of presumptive canal neuromasts (leaving pores between canal neuromasts; Tarby and Webb, 2003; Webb and Shirey, 2003). Morphogenesis of the canal is initiated around individual neuromasts in a series of four stages: I, IIa/b, III, and IV (Tarby and Webb, 2003; Figure 3A). Stage I is defined as when the neuromast is resting on the epithelium. Stage II is when the neuromast is located in an epithelial depression. Prior to canal wall ossification, the stage is defined as IIa, and when the canal walls form on either side of a presumptive canal neuromast, the stage is defined as stage IIb. Stage III occurs when the epithelium encloses over the neuromast. Stage IV occurs when the canal walls fuse over the neuromast within the dermis (Tarby and Webb, 2003). By definition, a pore is present only after two adjacent neuromasts have become enclosed in canal bone (Stage IV), and it represents the absence of bone in the canal roof where ossification has not occurred (Figure 3B). Two kinds of pores are distinguished - a bony pore is the absence of bone in the canal roof, whereas the epithelial pore is a small opening in the epithelium that overlies the canal. The fusion of these adjacent canal segments results in the typical poreneuromast-pore arrangement in the lateral line canal in adult fishes (Lekander, 1949; Webb and Northcutt, 1997). 
The lateral line system shows considerable morphological diversity. Five types of lateral line canals are found among fishes: narrow, narrow with expanded tubules, reduced, branched, and widened (Figure 4). Narrow canals are the most common and are characterized by cylindrical, well-ossified canals with regularly spaced small pores. Narrow canals are found in fishes that swim in the water column (Coombs et al., 1988). In contrast, widened canals are characterized by larger canal neuromasts and a canal roof that is not completely ossified. In these canals, relatively narrow bony bridges represent the remnants of the canal roof leaving large bony pores between them which are covered by an epithelium pierced by small pores (Denton and Gray, 1988; Coombs et al., 1988). The widened canal pattern has evolved convergently in approximately 15 families of teleosts, which inhabit areas with low hydrodynamic noise or areas where light is limited (Webb, 1989b), including benthic fishes and those that live in dark environments. These include, for instance, coastal marine drums, members of several deep-sea marine families (Marshall, 1996), some freshwater perches (Eurasian Ruffe; Janssen, 1997), and some cichlids (Konings, 1990; Schwalbe et al., 2012). Fish with widened canals tend to be more sensitive to hydrodynamic stimuli, and are particularly sensitive to low frequencies ( $<60 \mathrm{~Hz}$; Denton and Gray, 1989). Species with widened lateral line canals may feed in the dark, or on the bottom, relying on their lateral line system instead of vision for prey detection (Schwalbe et al., 2012).

Previous studies have compared the morphology and development of the lateral line canals in cichlid species with narrow and widened canals (including neuromast size and shape and canal diameter; Webb et al., 2014; Becker., 2013; Bird and Webb, 2014). An unexplored aspect of the lateral line canal system is the development of the pores that 
link the fluid in the canals to the fluid in the surrounding environment. The pores of narrow lateral line canals are morphologically distinct from the pores of widened canals in several ways. In narrow canals, the bony pores are smaller and similar in size to the epithelial pores. In contrast, in widened canals, the bony pores are much larger than the small pores in the epithelium overlying them. The epithelium covering the large bony pores between the adjacent bony bridges is thought to act as a tympanum, which can move in response to flows outside the canal and cause fluid movement within the canal, thus stimulating the canal neuromasts (Webb, 1989b).

Pore position and pore size are both likely to be critical for determining how canal neuromasts function. Neuromasts respond to a pressure difference in the fluid immediately outside neighboring pores, which induces flows in the canals (Denton and Gray, 1988). In narrow canals, the neuromasts are only stimulated by flows coming through relatively small canal pores. Since a canal contains multiple neuromasts and the fluid in the canal is free to move along its length, stimuli (water movement) entering several pores may affect a single neuromast (Coombs et al., 1988; Figure 1) or a stimulus (water movement) entering one pore may stimulate more than one neuromast (e.g. one neuromast is located on either side of a pore). It is known that the neuromasts in widened canals, can detect lower frequencies, and are more sensitive than neuromasts in narrow canals (Denton and Gray, 1988). This is thought to be due to the overlying epithelium's ability to move with changes in water pressure outside the canal, which then displace the fluid within the canal and the cupula of the canal neuromasts.

The goal of this project was to examine ontogenetic trends in size and shape of pores in two cichlid species, Aulonocara stuartgranti (which have widened canals) and 
Tramitichromis sp. (which have narrow canals) and to compare pores in two canals (supraorbital, mandibular) within each of the two species, Tramitichromis sp. (narrow canals) and Aulonocara stuartgranti (widened canals). These species will be referred to by their genus names for the rest of this thesis. Prior studies in the Webb Lab have focused on neuromast and canal development (Webb et. al., 2014; Bird and Webb, 2014; Becker, 2013). The data presented here are the first of their kind, showing ontogenetic trends of pore development from the larval stage (using histological analysis), through the juvenile stage, to adult (using methylene blue stained and cleared and stained specimens).

Six hypotheses based on prior studies of lateral line development in the Webb lab (Figure 5) were tested and are as follows: Hypothesis 1: pore number decreases as fish size increases and decreases at the same rate for the two species. Hypothesis 2: bony pore width (in the medio-lateral axis) decreases at a faster rate in narrow-canal species (Tramitichromis) than in widened-canal species (Aulonocara) as fish size increases, thus accounting for the differences in the size of the bony pores in adult fishes. Hypothesis 3 : the width of epithelial pores decreases at the same rate in both species. Hypothesis 4: the ratio of both bony and epithelial pore length (in the rostro-caudal axis) to standard length decreases as fish size increases and does so at the same rate in both species. Hypothesis 5: both bony and epithelial pore area decrease after initial pore formation and decrease at the same rate in both species. Hypothesis 6: the distance between both bony and epithelial pores increases as fish size increases and increases at the same rate in both species. 


\section{MATERIALS AND METHODS}

Cichlid fishes are a good taxon to use when studying the morphology and development of the lateral line system because they are commercially available, easily reared in the lab, and closely related species have divergent canal morphologies. Tramitichromis sp. and Aulonocara stuartgranti are endemic to Lake Malawi and are maternal mouth brooders. Fish were obtained from were obtained from Old World Exotic Fish, Inc., (Homestead, FL, USA) or Live Fish Direct (Draper, UT, USA; Tramitichromis) and from Bluegrass Aquatics (Louisville, KY, USA; Aulonocara). Breeding tanks in two flow- through systems were lined with a mixture of sand and gravel, provided with mechanical and biological filtration and kept at $80 \pm 1^{\circ} \mathrm{F}(26.6$ $\pm 1^{\circ} \mathrm{C}$ ) and salinity of $1 \pm 0.5 \mathrm{ppt}$ with a 12 hour: 12 hour light:dark light regime. A breeding group of one male and several females were placed in tanks with rock structures in an attempt to mimic their natural environment. Animals were fed daily on a varied diet (protein pellets, live brine shrimp, a pea/shrimp mixture, or an algae/yolk/earthworm protein flake mixture). Tanks were checked daily for new broods and an expanded buccal cavity, decreased swimming activity, and lack of feeding indicated that fertilization had occurred in the last 24 hours. Broods were removed from the mother's mouth by gently flushing the mouth with a pipette of tank water and were then raised in a recirculating rack system. After yolk sac absorption, the larvae were fed plankton pellets and then switched onto flake food (equal parts egg yolk, earthworm and then pellets). Ontogenetic series of Aulonocara and Tramitichromis were collected at 2-3mm SL (standard length) growth intervals. Fish were anaesthetized with MS-222 (ethyl 3-aminobenzoate methanesulfonate) and fixed in $10 \%$ formalin in phosphate buffered saline (PBS) () 
following an approved IACUC protocol. Histology (Hall, 1986), methylene-blue staining, and cleared and stained techniques (Potthoff, 1984) were used because one technique could not show both bony and epithelial pores in fishes at all size ranges (8-59 $\mathrm{mm} \mathrm{SL})$. Histology was used on smaller individuals $(8-19.5 \mathrm{~mm})$ allowing visualization of both bony and epithelial pores. Methylene blue stain and cleared and stained fishes were used for larger individuals $(16-59 \mathrm{~mm})$. Fish size in this study is defined as standard length (SL). Methylene blue stain showed the epithelial pores and cleared and stained fish revealed the bony pores allowing measurements to be taken for both types of pores (Figure 6,7).

\section{Histology}

Histological material used in this study was previously prepared (see Bird and Webb, 2014) from broods of Aulonocara $(\mathrm{n}=14,11-19.5 \mathrm{~mm})$ and Tramitichromis $(\mathrm{n}=$ 16, 8-17mm). Fish $>6 \mathrm{~mm}$ SL were decalcified in Cal-Ex (Fisher) for 2 hours $(6-7.5 \mathrm{~mm}$ $\mathrm{SL}), 3.5$ hours $(8-8.5 \mathrm{~mm})$ or $7-8$ hours $(>8.5 \mathrm{~mm} \mathrm{SL})$, then rinsed in phosphate buffer and dehydrated in an ascending ethanol and t-butyl alcohol series and embedded in Paraplast Plus. Serial transverse sections of the whole head were cut at $8 \mu \mathrm{m}$, mounted on slides subbed with $10 \%$ albumin in $0.9 \% \mathrm{NaCl}$, and stained with a modified $\mathrm{HBQ}$ stain (Hall, 1986). Data collection was limited to individuals in which canal formation had started and in which pores could be reliably identified and measured. The same histological material had been previously used to record canal stage, measure canal diameter and canal width, and calculate length (Bird and Webb, 2014), which facilitated the identification of specimens used for this project. Images were captured with a Zeiss 
AxioImager1 compound microscope attached to a Mac computer equipped with Axiovision software (v. 4.6.3), which was used to make measurements at $20 \mathrm{x}$ magnification. Using histological data, SO and MD canal pore widths were measured at the rostral-caudal midpoint of each pore, laterally, from edge to edge. (Figure 6A, 7A). Pore length and distance between pores were calculated by counting the number of sections in which the pore (or lack of pore) was present and multiplying by $8 \mu \mathrm{m}$ (section thickness). Four pores were present in both the mandibular and supraorbital canals (plus one terminal pore at the rostral end of each canal and one terminal pore at the caudal end of each canal; Figure 8).

\section{Methylene blue staining and preparation of cleared and stained specimens}

Fish comprising ontogenetic series of Aulonocara $(n=21,16-59 \mathrm{~mm} \mathrm{SL})$ and Tramitichromis $(\mathrm{n}=21,16.5-55 \mathrm{~mm} \mathrm{SL})$ were anaesthetized with a $0.04 \%$ solution of buffered MS222 and fixed in 10\% formalin in PBS. After fixation for at least 24 hours, fish were bleached with a $15 \%$ solution of hydrogen peroxide in $1 \%$ potassium hydroxide for an hour to bleach the melanophores. They were then stained in $0.05 \%$ methylene blue for up to 15 minutes depending on the size of the specimen. These same specimens were then enzymatically cleared and stained for bone and cartilage (Potthoff, 1984) to analyze the size and area of bony pores.

Pictures were taken of both methylene blue stained and cleared and stained specimens on a Nikon dissecting scope using a Spot digital camera attached to a Mac computer equipped with Spot image acquisition and processing software (v. 5.0, Diagnostic Instruments). All measurements were taken at 20x magnification. For the 
methylene blue and cleared and stained data, pore width (in the medio-lateral axis) and length (in the rostro-caudal axis) were measured from one outside edge to the opposite outside edge of the bony or epithelial pore (Figure 6,7). The linear distance between pores (interpore distance) was measured from the caudal edge of a pore to the rostral end of the next pore closest to it (Figure 6,7). Cross-sectional area of a pore was calculated using the measurements taken for length (PL) and width $(\mathrm{PW})\left(\right.$ Area $=\pi^{*}(1 / 2) \mathrm{PL} *(1 / 2)$ PW). Measurements were made using ImageJ software (v. 1.45s) from images captured using Spot software.

\section{Statistical Analysis}

Statistical analysis of each of the measured variables was carried out using JMP (v. 10.0.2, SAS Institute). Data were tested for normality and linearity (Goodness of Fit tests; JMP, v. 10.0.2, SAS Institute, Inc, Cary, North Carolina, USA). If the data were not normal, they were log-transformed and then used for regression analysis. Analysis of Variance (ANOVA) was used to determine if the slope of a regression line was significantly different from zero. If so, Analysis of Covariance (ANCOVA) was used to detect differences in slopes between species for the following parameters (for bony and for epithelial pores); pore width, pore length, ratio of pore length to fish size, crosssectional area of the pore, and distance between pores. Each of these statistical tests was carried out using pore data from MD and SO canals combined, MD canal only, and SO canal only. The significance level used for all tests was 0.05. A student's T-test was used where non-significant differences in slope (ANCOVA) were found to determine if an elevation difference was present for two regressions. It was determined that differences in 
left vs. right data were not significant so all canal measurements were analyzed with left and right data combined. 


\section{RESULTS}

Aulonocara and Tramitichromis differ with reference to the shape and size of their canal pores. Tramitichromis has relatively small bony and epithelial pores, and canals and pores form a bit earlier in ontogeny. Aulonocara has both larger and wider bony pores that form a bit later relative to those in Tramitichromis. For all variables analyzed, Aulonocara have higher values than Tramitichromis (i.e. larger pores;

ANCOVA, Table 3). In general, pores show an ontogenetic trend towards a more oval shape, but there is variation in shape among pores within an individual and between species, which was not analyzed here.

The locations of pores within the MD and SO canals were the same in the two species (Figure 8). Only pores $\mathrm{C}$ and $\mathrm{E}$ in the $\mathrm{SO}$ canal were analyzed in cleared and stained individuals in larger specimens. Bony pore D is not a true bony "pore". It is the opening between the portions of the SO canal in the nasal bone and frontal bone. Pore D is the common medial pore formed by the joining of the medial-facing tubules of the right and left SO canals - it is represented by an epithelial pore. In the MD canal, bony pores B, C, and D (within the dentary bone) were analyzed; Pore E is the opening between the dentary and the anguloarticular bones and was not included in the analysis (Figure 8). In the MD canal, pore D forms earlier in ontogeny and pore B forms much later in ontogeny (as in Bird and Webb, 2014). All of the pores face ventrally, but pore C faces more laterally. In both species, the SO canal tends to ossify in a caudal to rostral direction (Bird and Webb, 2014), so that pore $\mathrm{E}$ is the first pore to form and pore B is the last pore to form. The SO canal pores tend to form earlier in ontogeny than do those in the MD canal (Table 1). 
The bony pores are larger than the epithelial pores in both Aulonocara and Tramitichromis, but in Aulonocara, the bony pores are much larger than the epithelial pores. In Tramitichromis, the epithelial pores are much closer to the size of the bony pores (Figure 9). These relationships are key features that help distinguish narrow canals from widened canals.

\section{Number of Pores (Hypothesis 1)}

A bony pore is visible only after two neuromasts have become enclosed in adjacent canal segments. Epithelial pores form when adjacent segments are both at Stage III before the bony pores are fully formed as the result of canal ossification (Stage IV). The bony pores are not yet present in young larvae in which the canals have not yet formed, but are present in late-stage larvae, juveniles and adults as canals ossify.

Pore number initially increases as canals segments initially form, but pore number should decrease as pores of individual segments begin to fuse. It was hypothesized that the number of pores would decrease as fish size increases at the same rate in both Aulonocara and Tramitichromis. However, once a canal has become fully ossified and adjacent segments have fused, the number of bony pores is fixed. In Aulonocara, four epithelial pores can be seen in the SO canal in fish $18 \mathrm{~mm}$ SL, and in the MD canal in fish $25 \mathrm{~mm}$ SL. With respect to bony pores, a full set of fully ossified bony pores can be found in the SO canal in fish of about $28 \mathrm{~mm} \mathrm{SL}$. There is a slight delay in ossification of the MD canal, so that all four MD pores are not seen until much later in ontogeny (40 mm SL; Table 1). In Tramitichromis, four epithelial pores are found in the SO canal at 13-15 mm SL, and at about $19.5 \mathrm{~mm} \mathrm{SL}$ in the MD canal (Table 1). Four ossified bony 
pores can be found in the SO canal earlier (at about 13-15 mm SL) and in fish of about the same size fish (24 mm SL) in the MD canal. In larger specimens of both species, the number of epithelial pores outnumbered the bony pores in 58 of 67 specimens starting at $8 \mathrm{~mm} \mathrm{SL}$ (Table 1). This can be explained by the proliferation of epithelial pores in which multiple epithelial pores are found in association with a single bony pore in larger specimens (Figure 10). This is explained by the branching of the tubules within the epithelium emerging from the location of each bony pore (see also Peters, 1973).

\section{Pore Width (Hypothesis 2 and 3)}

Bony pore width and epithelial pore width were analyzed separately in larvae and small juveniles (8-19.5 mm SL) using histological material, and in older juveniles and adults (16-59 mm SL) using cleared and stained (bony pores) and methylene blue (epithelial pores) stained individuals. It has been hypothesized that bony pore width would decrease in both species and at a faster rate in Tramitichromis than in Aulonocara. In addition, it had been hypothesized that epithelial pore width would decrease and at the same rate in both species. Results of ANOVA and ANCOVA analyses, as cited below, are in Tables 2 and 3.

In larvae and small juveniles (8-19.5 mm SL), bony pore width (SO and MD canals combined) increased in both Aulonocara and Tramitichromis, but at a very slow rate $(0.13 \mu \mathrm{m} / \mathrm{mm}$ SL, $0.07 \mu \mathrm{m} / \mathrm{mm}$ SL respectively; ANOVA, $\mathrm{p}<0.0001, \mathrm{p}=0.0109$ respectively), which is statistically the same in both species (ANCOVA, $p=0.1436$; Figure 11A). In the MD canal, bony pore width did not change in either Aulonocara or Tramitichromis (ANOVA, $\mathrm{p}=0.3717, \mathrm{p}=0.1075$ respectively; ANCOVA, $\mathrm{p}=0.0821$ ). In 
Aulonocara, bony pore width was $\sim 170 \mu \mathrm{m}$ in fish of $15 \mathrm{~mm}$ SL and increased to $\sim 240$ $\mu \mathrm{m}$ in fish of $20 \mathrm{~mm}$ SL. In Tramitichromis, bony pore width was $\sim 120 \mu \mathrm{m}$ in fish of 11 $\mathrm{mm} \mathrm{SL}$ and increased to $\sim 75 \mu \mathrm{m}$ in fish of $17 \mathrm{~mm} \mathrm{SL}$. In the MD canal, pore width is not statistically significant due most likely to the lack of data points available. In the SO canal, bony pore width increased, and at the same rate in both Aulonocara and Tramitichromis (ANOVA, $\mathrm{p}=0.0004, \mathrm{p}=0.0011$ respectively; ANCOVA, $\mathrm{p}=0.5864$ ). In Aulonocara, bony pore width was $\sim 50 \mu \mathrm{m}$ in fish $11 \mathrm{~mm} \mathrm{SL}$ and increased almost fourfold to $\sim 190 \mu \mathrm{m}$ at $20 \mathrm{~mm}$ SL. In Tramitichromis, bony pore width was $\sim 60 \mu \mathrm{m}$ wide in fish of $11 \mathrm{~mm} \mathrm{SL}$ and $\sim 95 \mu \mathrm{m}$ at $17 \mathrm{~mm}$ SL, which was a significant increase in width. In all three analyses (canal combined, and MD and SO considered separately), bony pore width was consistently larger in Aulonocara than in Tramitichromis (t-test, $\mathrm{t}=1.9806$, $\mathrm{t}=2.0860$, and $\mathrm{t}=1.9861$ respectively).

In larger, cleared and stained juveniles and adults (16-59 mm SL), bony pore width (SO and MD canals combined) increased slowly, and at the same rate, in both Aulonocara and Tramitichromis (ANOVA, $\mathrm{p}<0.0001, \mathrm{p}<0.0001$ respectively; ANCOVA, $\mathrm{p}=0.8464$; Figure 11B). In the MD canal, bony pore width increased in both species (ANOVA, $\mathrm{p}<0.0001$ in each species), but increased $\sim 1.8 \mathrm{x}$ faster in Aulonocara than in Tramitichromis (ANCOVA, $\mathrm{p}=0.0136$ ). For instance, bony pores were $\sim 300 \mu \mathrm{m}$ in Aulonocara at $20 \mathrm{~mm} \mathrm{SL}$ and more than doubled to $\sim 700 \mu \mathrm{m}$ at $59 \mathrm{~mm}$ SL. In the MD of Tramitichromis, bony pore width was $\sim 170 \mu \mathrm{m}$ at $20 \mathrm{~mm}$ SL but increased a bit, to $\sim 210$ $\mu \mathrm{m}$ in fish of $55 \mathrm{~mm}$ SL. In the SO canal, bony pore width increased slowly in both species (ANOVA, $\mathrm{p}=<0.0001, \mathrm{p}<0.0001$ in each species), but appeared to increase slightly faster in Aulonocara than in Tramitichromis (ANCOVA, $\mathrm{p}=0.0544$ ). In the SO 
canal of Aulonocara, bony pore width was $\sim 290 \mu \mathrm{m}$ at $20 \mathrm{~mm} \mathrm{SL}$ and $\sim 470 \mu \mathrm{m}$ at $59 \mathrm{~mm}$ SL. In Tramitichromis, bony pore width was $\sim 165 \mu \mathrm{m}$ at $20 \mathrm{~mm}$ SL and doubled to $\sim 300$ $\mu \mathrm{m}$ at $55 \mathrm{~mm} \mathrm{SL}$. In both the analysis of MD and SO and in the analysis of the SO canal alone, Aulonocara consistently had wider bony pores than Tramitichromis (t-test, $\mathrm{t}=1.9702, \mathrm{t}=1.9788$, for the MD and SO canals, respectively).

In contrast to bony pore width, epithelial pore width tends to increase and then decrease as fish increase in size. In larvae and small juveniles prepared histologically (819.5 mm SL), epithelial pore width (MD and SO canals combined) increased at the same rate in both Aulonocara and Tramitichromis (ANOVA, $\mathrm{p}<0.0001, \mathrm{p}<0.0001$ respectively; ANCOVA, $\mathrm{p}=0.2029$; Figure 11C). In the MD canal, Aulonocara and Tramitichromis showed the same rate of increase in epithelial pore width (ANOVA, $p=0.0008$, $\mathrm{p}=0.0106$, respectively; ANCOVA, $\mathrm{p}=0.8332$ ). In Aulonocara, epithelial pore width was $\sim 60 \mu \mathrm{m}$ at $12 \mathrm{~mm}$ SL and much larger, $\sim 135 \mu \mathrm{m}$ in a fish $20 \mathrm{~mm}$ SL. In Tramitichromis, epithelial pore width was $\sim 50 \mu \mathrm{m}$ in fish $12 \mathrm{~mm}$ SL, but just a bit larger, $\sim 75 \mu \mathrm{m}$ at 17 $\mathrm{mm}$ SL. In the SO canal, epithelial pore width increased, and at the same rate in both species (ANOVA, $\mathrm{p}<0.0001, \mathrm{p}<0.0001$, both species; ANCOVA, $\mathrm{p}=0.3586$ ). Epithelial pore width in the SO canal in Aulonocara was $\sim 50 \mu \mathrm{m}$ at $12 \mathrm{~mm} \mathrm{SL}$ and $\sim 120 \mu \mathrm{m}$ at 20 mm SL. In Tramitichromis, epithelial pore width was $\sim 50 \mu \mathrm{m}$ at $12 \mathrm{~mm}$ SL and $\sim 70 \mu \mathrm{m}$ at $17 \mathrm{~mm}$ SL. In all three analyses (combined, and MD and SO considered separately), epithelial pore width was consistently larger in Aulonocara than in Tramitichromis (t-test, $\mathrm{t}=1.9727, \mathrm{t}=2.0117, \mathrm{t}=1.9774$, respectively).

In larger juveniles and adults stained with methylene blue (16-59 mm SL), epithelial pore width (MD and SO canal data combined) did not increase, but decreased 
in both Aulonocara and Tramitichromis (ANOVA $\mathrm{p}=0.0354, \mathrm{p}<0.0001$, respectively) and decreased 2.6x faster in Tramitichromis than in Aulonocara (ANCOVA, $\mathrm{p}=0.0077$;

Figure 11D), resulting in smaller pores. In the MD canal, epithelial pore width did not change in Aulonocara or Tramitichromis (ANOVA, $\mathrm{p}=0.9093, \mathrm{p}=0.1200$, respectively; ANCOVA, $\mathrm{p}=0.2478$ ), but Aulonocara had epithelial pore widths that were consistently larger than those in Tramitichromis ( $\mathrm{t}$-test, $\mathrm{t}=1.9673$ ). In the MD canal in Aulonocara, epithelial pore width was $\sim 180 \mu \mathrm{m}$ in a fish $20 \mathrm{~mm} \mathrm{SL}$ and $\sim 200 \mu \mathrm{m}$ in a fish $59 \mathrm{~mm}$ SL, which is a non-significant difference. In Tramitichromis, epithelial pore width was $~ 140$ $\mu \mathrm{m}$ at $20 \mathrm{~mm} \mathrm{SL}$ and $\sim 120 \mu \mathrm{m}$ at $55 \mathrm{~mm}$ SL, which was not a statistically significant change. In contrast to the MD canal, epithelial pore width in the SO canal decreased in these larger animals in both Aulonocara and Tramitichromis (ANOVA, $\mathrm{p}=0.0005$, $\mathrm{p}<0.0001$, respectively), and decreased in Tramitichromis $\sim 2 \mathrm{x}$ faster than in Aulonocara (ANCOVA, $\mathrm{p}=0.0187$ ), resulting in smaller epithelial pores in Tramitichromis than in Aulonocara. In Aulonocara, SO epithelial pore width was $\sim 170 \mu \mathrm{m}$ in fish $20 \mathrm{~mm}$ SL and decreased to $\sim 130 \mu \mathrm{m}$ in fish $59 \mathrm{~mm}$ SL. In Tramitichromis, epithelial pore width was $\sim 150 \mu \mathrm{m}$ at $20 \mathrm{~mm}$ SL and decreased to $\sim 80 \mu \mathrm{m}$ at $55 \mathrm{~mm}$ SL.

Overall, bony pore width increased with fish size with the exception of the trend in the MD canal in larvae and juveniles (8-19.5 mm SL) in which bony pore width did not change significantly in either species. The combined (SO+MD) and SO data show there was no difference in the rate of change in bony pore width between species throughout ontogeny. Epithelial pore width in larvae and small juveniles (8-19.5 mm SL) changed at the same rate in both Aulonocara and Tramitichromis, but was consistently larger in Aulonocara. In contrast, epithelial pore width decreased in the SO and when 
combined canal data were considered in both species, but did not change in the MD in larger juveniles and adult fish.

\section{Pore Length}

Bony and epithelial pore length was analyzed separately in larvae and small juveniles (8-19.5 mm SL) in histological material, and in older juveniles and adults (16$59 \mathrm{~mm} \mathrm{SL}$ ) in cleared and stained (bony pores) and methylene blue (epithelial pores). Results of ANOVA and ANCOVA analyses, as cited below, are in Tables 2 and 3. In larvae and small juveniles (8-19.5 mm SL), bony pore length (SO and MD canals combined) increased in Aulonocara (ANOVA, $\mathrm{p}=0.0146$ ) and did not change in Tramitichromis (ANOVA, $\mathrm{p}=0.1364$ ), but the rate of change in bony pore length was not statistically different in the two species (ANCOVA, $p=0.1691$; Figure 12A). In the MD canal, bony pore length did not increase or decrease in either Aulonocara or Tramitichromis (ANOVA, $\mathrm{p}=0.5179, \mathrm{p}=0.4515$, respectively; ANCOVA, $\mathrm{p}=0.3280$ ). Due to a small number of data points, MD canal trends were found not to be significant. In Aulonocara, bony pore length was $\sim 500-780 \mu \mathrm{m}$ in fish $14-20 \mathrm{~mm}$ SL. In Tramitichromis, bony pore length was $\sim 200-250 \mu \mathrm{m}$ in fish $12-17 \mathrm{~mm}$ SL. In the SO canal, bony pore length increased in Aulonocara (ANOVA, $\mathrm{p}=0.0207$ ) and did not change in Tramitichromis (ANOVA, p=0.3007), For example, in Aulonocara, bony pore length in the SO canal was $\sim 175 \mu \mathrm{m}$ at $11 \mathrm{~mm}$ SL and increased to $\sim 400 \mu \mathrm{m}$ at $20 \mathrm{~mm}$ SL. In Tramitichromis, bony pore length was $\sim 175 \mu \mathrm{m}$ at $11 \mathrm{~mm}$ SL and approximately the same at $17 \mathrm{~mm}$ SL. However, it should be noted that that the rate of change in bony 
pore length was not statistically different between the two species (ANCOVA, $\mathrm{p}=0.1373)$.

In larger juveniles and adults (16-59 mm SL), bony pore length (SO and MD canals combined) increased at the same rate in both species (ANOVA, $p=<0.0001$ for both species; ANCOVA, $\mathrm{p}=0.5417$; Figure 12B). In both the MD and in the SO canals, bony pore length increased at the same rate in both species (ANOVA, $p<0.0001$ for species and in both canals; ANCOVA, $\mathrm{p}=0.189$ for the MD canal, $\mathrm{p}=0.8497$ for the SO canal, respectively). For example, in the MD canal in Aulonocara, bony pore length was $\sim 300 \mu \mathrm{m}$ at $16 \mathrm{~mm}$ SL and more than doubled to $\sim 720 \mu \mathrm{m}$ at $59 \mathrm{~mm}$ SL. In the MD canal in Tramitichromis, bony pore length was a bit smaller, $\sim 200 \mu \mathrm{m}$ at $16 \mathrm{~mm}$ SL and more than doubled to $\sim 420 \mu \mathrm{m}$ at $55 \mathrm{~mm}$ SL. Similar trends are seen in the SO canal. In the SO canal of Aulonocara, bony pore length was $\sim 300 \mu \mathrm{m}$ at $16 \mathrm{~mm}$ SL and $\sim 680 \mu \mathrm{m}$ at 59 mm SL. In the SO canal of Tramitichromis, bony pore length was $\sim 175 \mu \mathrm{m}$ at $16 \mathrm{~mm} \mathrm{SL}$ and $\sim 275 \mu \mathrm{m}$ at $55 \mathrm{~mm}$ SL.

Epithelial pore length showed similar trends between canals and between species. In larvae and small juveniles (8-19.5 mm SL), epithelial pore length (SO and MD canals combined) did not change in either Aulonocara or Tramitichromis (ANOVA, $\mathrm{p}=0.1485$, $\mathrm{p}=0.8195$, respectively; ANCOVA, $\mathrm{p}=0.1835$; Figure 12C). In the MD canal, epithelial pore length did not change in either Aulonocara or Tramitichromis (ANOVA, $\mathrm{p}=0.0966$, $\mathrm{p}=0.0621$ respectively). For example, MD epithelial pore length in Aulonocara was $\sim 180$ $\mu \mathrm{m}$ in fish at $11 \mathrm{~mm} \mathrm{SL}$ and $\sim 200 \mu \mathrm{m}$ in fish at $20 \mathrm{~mm} \mathrm{SL}$, which is not a statistically significant difference. In Tramitichromis, MD epithelial pore length was smaller, $\sim 90 \mu \mathrm{m}$ at $11 \mathrm{~mm}$ SL and $\sim 50 \mu \mathrm{m}$ at $17 \mathrm{~mm} \mathrm{SL}$, which was not a statistically significant trend. In 
the SO canal similar results were found with no significant ontogenetic change in epithelial pore length (ANOVA, $\mathrm{p}=0.517, \mathrm{p}=0.3127$, respectively). For instance, in Aulonocara, SO epithelial pore length was $\sim 180 \mu \mathrm{m}$ at $11 \mathrm{~mm} \mathrm{SL}$ and $\sim 200 \mu \mathrm{m}$ at 20 mm SL, which is not a significant increase. In Tramitichromis, SO epithelial pore length was smaller, $\sim 90 \mu \mathrm{m}$ at $11 \mathrm{~mm} \mathrm{SL}$ and $\sim 100 \mu \mathrm{m}$ at $17 \mathrm{~mm} \mathrm{SL}$. In both the MD canal and in the SO canal, the rate of change in epithelial pore length did not differ between species (ANCOVA $p=0.7654, p=0.2459$, respectively). In all three instances (combined data, MD and SO data considered separately), epithelial pore length in Aulonocara was consistently larger than in Tramitichromis (t-test, $\mathrm{t}=1.9725, \mathrm{t}=2.0117, \mathrm{t}=1.9772$ respectively).

In larger juveniles and adults (16-59 mm SL), with data from SO and MD canals combined, epithelial pore length did not change in Aulonocara (ANOVA, p=0.1536), whereas epithelial pore length decreased in Tramitichromis (ANOVA, $\mathrm{p}<0.0001$ ) than in Aulonocara (ANCOVA, p=0.0003; Figure 12D). In the MD canal, epithelial pore length decreased in both Aulonocara and Tramitichromis (ANOVA, $\mathrm{p}=0.0276, \mathrm{p}<0.011$ respectively), and at a rate that is $\sim 2 \mathrm{x}$ faster in Tramitichromis than in Aulonocara (ANCOVA, $\mathrm{p}=0.0008$ ). For example, in Aulonocara, MD epithelial pore length was $\sim 200 \mu \mathrm{m}$ at $16 \mathrm{~mm}$ SL and $\sim 330 \mu \mathrm{m}$ at $59 \mathrm{~mm}$ SL. In Tramitichromis, epithelial pore length was $\sim 200 \mu \mathrm{m}$ at $16 \mathrm{~mm} \mathrm{SL}$, but decreased to $\sim 150 \mu \mathrm{m}$ at $40 \mathrm{~mm}$ SL. In the SO canal, epithelial pore length decreased at the same rate in Aulonocara and Tramitichromis (ANOVA, $\mathrm{p}<0.0001$ for both species; ANCOVA, $\mathrm{p}=0.1478$ ). In the SO canal of Aulonocara, epithelial pore length was $\sim 200 \mu \mathrm{m}$ at $16 \mathrm{~mm}$ SL and decreased to $\sim 125 \mu \mathrm{m}$ at $59 \mathrm{~mm}$ SL. In Tramitichromis, SO epithelial pore length was $\sim 150 \mu \mathrm{m}$ at $16 \mathrm{~mm} \mathrm{SL}$ 
and decreased to $\sim 75 \mu \mathrm{m}$ at $55 \mathrm{~mm}$ SL. In the SO canal, epithelial pore length was always greater in Aulonocara than in Tramitichromis ( $\mathrm{t}$-test, $\mathrm{t}=1.9673$ ).

Overall, bony and epithelial pore length show interesting ontogenetic trends. Bony pore length did not change with fish size in smaller individuals of either species (8$19.5 \mathrm{~mm} \mathrm{SL})$, but bony pore length increased in larger individuals (16-59 mm SL). The rate of change in bony pore length was not different between the two species, for either size range, but Aulonocara had consistently larger bony pore lengths than Tramitichromis. In contrast, the rate of change of epithelial pore length in smaller individuals was not different from zero in either species, but epithelial pore length decreased in larger individuals (with exception of pores within MD canal of Aulonocara). Epithelial pore length decreased faster in Tramitichromis than in Aulonocara when data from both canals $(\mathrm{MD}+\mathrm{SO})$ and the MD canal alone were analyzed.

\section{Ratio of Pore Length to Standard Length (Hypothesis 4)}

The analysis of the ratio of pore length to fish size (derived from data above, see Tables 2 and 3) shows how pore length changes relative to fish size. It had been hypothesized that the ratio of pore length to fish size would not change as fish size increases in both species. This hypothesis was supported - in larvae and early juveniles (8-19.5 $\mathrm{mm} \mathrm{SL})$, bony pore data from the MD and SO canals combined show that the rate of change of the ratio of bony pore length to fish size was not different from zero in either Aulonocara and Tramitichromis (ANOVA, $\mathrm{p}=0.3097, \mathrm{p}=0.6113$ respectively; ANCOVA, $\mathrm{p}=0.2237)$. In the MD canal and in the SO canal, neither Aulonocara nor Tramitichromis had a rate of change in the ratio of bony pore length to fish size that was 
different from zero (ANOVA, $p=0.274, p=0.7233$ respectively $[M D] ; p=0.3506$, $\mathrm{p}=0.2564$ respectively $[\mathrm{SO}])$. There was no difference in the rate of change in the ratio between the two species for either the MD canal or in the SO canal (ANCOVA, $\mathrm{p}=$ $0.2103, \mathrm{p}=0.1717$ respectively).

Larger juveniles and adults (16-59 $\mathrm{mm} \mathrm{SL}$ ) that were cleared and stained revealed that the ratio of bony pore length to fish size decreased with fish size, and at the same rate in both species (data from MD and SO canals combined, ANOVA, $\mathrm{p}<0.0001, \mathrm{p}<0.0001$ for both species; ANCOVA, $\mathrm{p}=0.1059)$. In the MD canal, the ratio of bony pore length to fish size decreased, and at the same rate in both species (ANOVA, $\mathrm{p}=<0.0001$ for both species; ANCOVA, $\mathrm{p}=0.7377$ ). In the SO canal, the ratio of bony pore length decreased (ANOVA, $\mathrm{p}<0.0001, \mathrm{p}<0.0001$, respectively) at a rate that was $\sim 1.8 \mathrm{x}$ faster in Aulonocara than in Tramitichromis (ANCOVA, $\mathrm{p}=0.0476$ ).

The same histological material used for bony pore length analysis, with data from MD and SO canals combined, showed no change in the ratio of epithelial pore length to fish size in Aulonocara (ANOVA, p=0.3818), while the ratio decreased in Tramitichromis (ANOVA, $\mathrm{p}<0.0001$ ). However, the rate of change of the ratios were the same in both species (ANCOVA, $\mathrm{p}=0.701)$.

In larger juveniles and adults (16-59 $\mathrm{mm} \mathrm{SL})$ stained with methylene blue (data from MD and SO canals combined) the ratio of epithelial pore length to fish size in the two species decreased, and at the same rate (ANOVA, $\mathrm{p}<0.0001$ for both species; ANCOVA, $\mathrm{p}=0.5218)$.

Overall, the ratio of bony pore length to fish size showed a different ontogenetic trend in small versus larger individuals in both Aulonocara and Tramitichromis. In both 
species, smaller individuals showed no ontogenetic change in the ratio of bony pore length to fish size (isometry) while in larger individuals the ratio of bony pore length to fish size decreased ontogenetically (the fish was growing faster than the pores). In all instances, the rate of change in the ratio was the same in both species, with the exception of the SO canal where the ratio decreased faster in Aulonocara than in Tramitichromis.

In contrast, the ratio of epithelial pore length to fish size (SO+MD combined) showed a greater number of species differences. In smaller individuals, the ratio of epithelial pore length to fish size decreased ontogenetically in Tramitichromis, but did not change in Aulonocara, but there was no statistical difference between the rates of change in the ratios in the two species. In larger individuals, the ratio of epithelial pore length to fish size decreased ontogenetically in both species with no difference between the slopes of the lines in either species.

\section{Pore Area (Hypothesis 5)}

Pore area was calculated as $\mathrm{PA}=\pi^{*}(1 / 2) \mathrm{PL}^{*}(1 / 2) \mathrm{PW}(\mathrm{PL}=$ pore length; $\mathrm{PW}=$ pore width) for bony and epithelial pores, and analyzed separately in larvae and small juveniles (8-19.5 mm SL) using histological material, and in older juveniles and adults (16-59 mm SL) using cleared and stained (for bony pores) and methylene blue stained fish (for epithelial pores). It was hypothesized that pore area would decrease at the same rate in both species as fish size increases.

In larvae and small juveniles (8-19.5 mm SL), bony pores increased in area in both species. The data from MD and SO canals combined showed an increase in area in both Aulonocara and Tramitichromis (ANOVA, $\mathrm{p}=0.0023,0.0215$ respectively), but 
bony pore area increased much faster in Aulonocara than in Tramitichromis (ANCOVA, $\mathrm{p}=0.0022$; Figure 13A). In the MD canal, bony pore area did not change with fish size in Aulonocara or in Tramitichromis (ANOVA, $\mathrm{p}=0.9794, \mathrm{p}=0.6388$, respectively; ANCOVA, $\mathrm{p}=0.9107)$. For example, in Aulonocara, MD bony pore area was $\sim 0.4 \mathrm{~mm}^{2}$ at $14 \mathrm{~mm} \mathrm{SL}$ and approximately the same at $20 \mathrm{~mm}$ SL, a statistically non-significant change in pore area. In Tramitichromis, bony pore area was $\sim 0.05 \mathrm{~mm}^{2}$ at $11 \mathrm{~mm}$ SL and doubled to $\sim 0.1 \mathrm{~mm}^{2}$ at $17 \mathrm{~mm}$ SL, but this was not a statistically significant change. However, in the SO canal, bony pore area increased in both Aulonocara and in Tramitichromis (ANOVA, $\mathrm{p}=0.0122, \mathrm{p}=0.0119$, respectively), but increased faster in Aulonocara than in Tramitichromis (ANCOVA, $\mathrm{p}=0.0061$ ). For example, in Aulonocara, bony pore area was $\sim 0.025 \mathrm{~mm}^{2}$ in fish at $12 \mathrm{~mm} \mathrm{SL}$ and increased more than ten-fold to $\sim 0.33 \mathrm{~mm}^{2}$ in fish at $20 \mathrm{~mm}$ SL. In Tramitichromis, bony pore area was $\sim 0.025 \mathrm{~mm}^{2}$ at $11 \mathrm{~mm} \mathrm{SL}$ and doubled to $\sim 0.05 \mathrm{~mm}^{2}$ at $17 \mathrm{~mm} \mathrm{SL}$.

Similar results were seen in larger juveniles and adults (16-59 $\mathrm{mm} \mathrm{SL).} \mathrm{Bony} \mathrm{pore}$ area in MD and SO canals (data combined) increased in both Aulonocara and Tramitichromis (ANOVA, $\mathrm{p}<0.0001$ for each species), but at a rate that was $\sim 3.4$ times higher in Aulonocara than in Tramitichromis, (ANCOVA, p<0.0001; Figure 13B) resulting in much larger pores. In the MD canal, both species showed an increase in bony pore area (ANOVA, $\mathrm{p}<0.0001$ for each species), but in Aulonocara bony pore area increased $\sim 4.7 \mathrm{x}$ faster than in Tramitichromis, (ANCOVA, $\mathrm{p}<0.0001$; Figure 13E) again resulting in much larger pores. For example, in Aulonocara, bony pore area was $\sim 0.25$ $\mathrm{mm}^{2}$ at $20 \mathrm{~mm} \mathrm{SL}$ and increased by $\sim$ six-fold to $1.5 \mathrm{~mm}^{2}$ at $59 \mathrm{~mm}$ SL. In Tramitichromis, bony pore area was $\sim 0.2 \mathrm{~mm}^{2}$ at $20 \mathrm{~mm} \mathrm{SL}$ and increased slightly to 
$\sim 0.35 \mathrm{~mm}^{2}$ at $55 \mathrm{~mm} \mathrm{SL}$. In the SO canal, bony pore area increased in both species with fish size (ANOVA, $\mathrm{p}<0.0001$ for each species) and in Aulonocara increased at a rate that was $\sim 2.4 \mathrm{x}$ faster than in Tramitichromis (ANCOVA, $\mathrm{p}<0.0001$; Figure 12E). For example, in Aulonocara, bony pore area was $\sim 0.25 \mathrm{~mm}^{2}$ at $20 \mathrm{~mm}$ SL and increased fourfold to $\sim 1 \mathrm{~mm}^{2}$ at $59 \mathrm{~mm}$ SL. In Tramitichromis, bony pore area was $\sim 0.1 \mathrm{~mm}^{2}$ at $20 \mathrm{~mm}$ SL and increased three-fold to $\sim 0.3 \mathrm{~mm}^{2}$ at $55 \mathrm{~mm}$ SL.

Epithelial pore area showed similar ontogenetic trends to those of the bony pores. In larvae and small juveniles (8-19.5 mm SL), using data from MD and SO canals combined, both Aulonocara and Tramitichromis showed an increase in epithelial pore area with fish size (ANOVA, $\mathrm{p}=0.0135, \mathrm{p}<0.0001$, respectively), but epithelial pore area increased $\sim 12 \mathrm{x}$ faster in Aulonocara than in Tramitichromis (ANCOVA, $\mathrm{p}=0.0206$; Figure 13C). In the MD canal, epithelial pore area increased in both Aulonocara and Tramitichromis (ANOVA, $\mathrm{p}=0.0093, \mathrm{p}=0.0224$, respectively) and at the same rate (ANCOVA, $\mathrm{p}=0.2427$ ), but was consistently larger in Aulonocara than in Tramitichromis. In the MD canal of Aulonocara, epithelial pore area was $\sim 0.025 \mathrm{~mm}^{2}$ at $11 \mathrm{~mm} \mathrm{SL}$ and increased four-fold to $\sim 0.1 \mathrm{~mm}^{2}$ at $20 \mathrm{~mm}$ SL. In the MD canal in Tramitichromis, epithelial pore area increased very slowly from 8 to $17 \mathrm{~mm}$ SL from $\sim 0$ to $0.001 \mathrm{~mm}^{2}$. In the SO canal, epithelial pore area did not change in Aulonocara (ANOVA, $\mathrm{p}=0.0718$ ), but increased in Tramitichromis (ANOVA, $\mathrm{p}=0.001$ ). For instance, In Aulonocara, SO epithelial pore area was $\sim 0.03-0.12 \mathrm{~mm}^{2}$ in fish 11-59 $\mathrm{mm}$ SL. In Tramitichromis, epithelial pore area increased slowly, and was $\sim 0.001$ in fish $8 \mathrm{~mm}$ SL and just slightly larger in fish $17 \mathrm{~mm}$ SL. 
In larger juveniles and adults (16-59 $\mathrm{mm} \mathrm{SL})$, epithelial pore area did not change in Aulonocara (MD and SO data combined; ANOVA, $\mathrm{p}=0.1448$ ), but decreased in Tramitichromis (ANOVA, $\mathrm{p}<0.0001$ ), which is reflective of a difference in rate of change between species (ANCOVA, $\mathrm{p}=0.0008$; Figure 13D). In the MD canal, epithelial pore area in Aulonocara increased (ANOVA, $\mathrm{p}=0.0046$ ) whereas epithelial pore area in Tramitichromis did not change (ANOVA, $\mathrm{p}=0.1226$ ). For example, in Aulonocara, epithelial pore area was $\sim 0.1 \mathrm{~mm}^{2}$ at $20 \mathrm{~mm} \mathrm{SL}$ and increased to $\sim 0.25 \mathrm{~mm}^{2}$ at $59 \mathrm{~mm}$ SL, and in Tramitichromis, epithelial pore area in the MD canal was also $\sim 0.1 \mathrm{~mm}^{2}$ at 20 $\mathrm{mm}$ SL and only $\sim 0.08 \mathrm{~mm}^{2}$ at $55 \mathrm{~mm} \mathrm{SL}$, which was not a significant change. The rate of change in epithelial pore area in the MD canal was greater in Aulonocara than in Tramitichromis (ANCOVA, $\mathrm{p}=0.0007$ ). However, in the $\mathrm{SO}$ canal of both species epithelial pore area decreased at the same rate (ANOVA, $\mathrm{p}=0.0005, \mathrm{p}<0.0001$, respectively; ANCOVA, $\mathrm{p}=0.4357$ ). In Aulonocara, $\mathrm{SO}$ epithelial pore area was $\sim 0.1$ $\mathrm{mm}^{2}$ at $20 \mathrm{~mm}$ SL and decreased to $\sim 0.05 \mathrm{~mm}^{2}$ at $59 \mathrm{~mm}$ SL. In Tramitichromis, epithelial pore area was also $\sim 0.1 \mathrm{~mm}^{2}$ at $20 \mathrm{~mm} \mathrm{SL}$ and $\sim 0.02 \mathrm{~mm}^{2}$ at $55 \mathrm{~mm}$ SL indicating a statistically significant decrease in pore size.

Overall, bony pore area increased throughout ontogeny. In both larvae and small juveniles (8-19.5 mm SL) and in older juveniles and adults (16-59 $\mathrm{mm} \mathrm{SL}$ ) bony pore area increased with fish size in both species. Epithelial pore area also increased throughout ontogeny, but showed interspecific differences in trends in larger juveniles and adults. In larvae and small juveniles (8-19.5 mm SL), epithelial pore area increased (data from MD and SO canals combined) in both species. In older juveniles and adults 
(16-59 mm SL) epithelial pore area did not change in Aulonocara, whereas in

Tramitichromis epithelial pore area increased with fish size.

Distance between Pores (Hypothesis 6)

The distance between pores within a canal was analyzed separately in larvae and small juveniles (8-19.5 mm SL) using histological material, and in older juveniles and adults (16-59 mm SL) using cleared and stained (bony pores) and methylene blue (epithelial pores) stained individuals. It was hypothesized that the distance between pores would increase at the same rate in both species. Results of ANOVA and ANCOVA analyses, as cited below, are in Tables 2 and 3.

The distance between pores was measured from the posterior edge of one pore to the anterior edge of the pore directly caudal to it (Figure 6,7). Larvae and early juveniles (8-19.5 $\mathrm{mm} \mathrm{SL}$ ) indicated that the distance between bony pores (MD+SO combined) did not change in Aulonocara (ANOVA, $\mathrm{p}=0.3086$ ), but increased in Tramitichromis (ANOVA, $\mathrm{p}=0.0017$ ), although the rate of change in bony inter-pore distance was not statistically different between the two species (ANCOVA, $\mathrm{p}=0.0913$; Figure 14A). For example, in the SO canal, the distance between bony pores in Aulonocara was $\sim 270 \mu \mathrm{m}$ in fish at $13.5 \mathrm{~mm} \mathrm{SL}$ and $\sim 300 \mu \mathrm{m}$ in fish at $20 \mathrm{~mm} \mathrm{SL}$, indicating no change. In Tramitichromis, the distance between bony pores was $\sim 150 \mu \mathrm{m}$ at $11 \mathrm{~mm}$ SL and increased to $\sim 340 \mu \mathrm{m}$ at $17 \mathrm{~mm}$ SL. Distance between bony pores did not change with fish size in Aulonocara (ANOVA, $\mathrm{p}=0.7160$ ), but the distance increased in Tramitichromis (ANOVA, $\mathrm{p}=0.0003$ ). There was no difference in the rates for 
Aulonocara and Tramitichromis (ANCOVA, $\mathrm{p}=0.2859$ ). The MD canal was analyzed, but statistical analysis was not done due to limited data points $(n=4)$.

Data from the MD canal in larger juveniles and adults (16-59 $\mathrm{mm} \mathrm{SL}$ ) showed that the distance between bony pores in both Aulonocara and Tramitichromis increased, and at the same rate (ANOVA, $\mathrm{p}=0.0002, \mathrm{p}<0.0001$, respectively; ANCOVA, $\mathrm{p}=0.1142$; Figure 14B). For example, in Aulonocara, the distance between bony pores was $\sim 120 \mu \mathrm{m}$ at $20 \mathrm{~mm} \mathrm{SL}$ and almost doubled to $\sim 230 \mu \mathrm{m}$ at $59 \mathrm{~mm}$ SL. In Tramitichromis, the distance between pores was $\sim 210 \mu \mathrm{m}$ at $20 \mathrm{~mm} \mathrm{SL}$ and increased dramatically to $\sim 820$ $\mu \mathrm{m}$ at $55 \mathrm{~mm}$ SL, although statistically the rate of change was the same in both species. Data on bony inter-pore distance in the SO canal could not be analyzed because only data for pores C and E (but not pore D) were analyzed (See Figure 8).

With respect to epithelial pores, the same histological material showed that the distance between epithelial pores increased in both Aulonocara and Tramitichromis, (data from $\mathrm{SO}$ and MD canals combined; ANOVA, $\mathrm{p}=0.0007, \mathrm{p}<0.0001$, respectively) and at the same rate in both species (ANCOVA, $\mathrm{p}=0.0913$; Figure 14C). However, in the MD canal, Aulonocara showed no change in epithelial inter-pore distance (ANOVA, $\mathrm{p}=0.2578$ ). The distance between epithelial pores in the MD canal was $\sim 300 \mu \mathrm{m}$ at 14 $\mathrm{mm} \mathrm{SL}$ and $\sim 450 \mu \mathrm{m}$ at $20 \mathrm{~mm}$ SL. Inter-pore distance in the MD canal in Tramitichromis was not analyzed due to a lack of MD data points. In the SO canal, both species showed the same rate of increase in the distance between epithelial pores (ANOVA, $\mathrm{p}<0.0001$ for each species; ANCOVA, $\mathrm{p}=0.0683$ ). In the $\mathrm{SO}$ canal in Aulonocara, the distance between epithelial pores was $\sim 200 \mu \mathrm{m}$ at $11 \mathrm{~mm}$ SL and 
increased to $\sim 700 \mu \mathrm{m}$ at $20 \mathrm{~mm}$ SL. In the SO canal Tramitichromis, distance between epithelial pores was $\sim 250 \mu \mathrm{m}$ at $9 \mathrm{~mm} \mathrm{SL}$ and doubled to $\sim 500 \mu \mathrm{m}$ at $17 \mathrm{~mm} \mathrm{SL}$.

In older juveniles and adults (16-59 mm SL), epithelial inter-pore distance (with data from MD and SO canals combined) increased, and at the same rate in both species (ANOVA, $\mathrm{p}<0.0001$ for each species; ANCOVA, $\mathrm{p}=0.2288$; Figure 14D). In both the MD and SO canals, inter-pore distance in both species increased (ANOVA $\mathrm{p}<0.0001$ for each canal in each species) while the rate of change between species was not significantly different for either the MD or SO canal (ANCOVA, $\mathrm{p}=0.5672,0.1076$ respectively; Figure 14E). In the MD canal, the distance between epithelial pores in Aulonocara was $\sim 500 \mu \mathrm{m}$ at $20 \mathrm{~mm}$ SL and tripled to $\sim 1500 \mu \mathrm{m}$ at $59 \mathrm{~mm}$ SL. In the MD canal in Tramitichromis, distance between epithelial pores was $\sim 500 \mu \mathrm{m}$ at $20 \mathrm{~mm}$ SL and nearly tripled to $\sim 1200 \mu \mathrm{m}$ at $55 \mathrm{~mm} \mathrm{SL}$. In the SO canal, however, the distance between epithelial pores in Aulonocara was $\sim 750 \mu \mathrm{m}$ at $20 \mathrm{~mm}$ SL and $\sim 2500 \mu \mathrm{m}$ at $59 \mathrm{~mm}$ SL. In Tramitichromis, the distance between epithelial pores was $\sim 750 \mu \mathrm{m}$ at $20 \mathrm{~mm}$ SL and more than doubled to $\sim 2000 \mu \mathrm{m}$ at $55 \mathrm{~mm}$ SL.

Overall, distance between bony pores in both species, and in both canals increased and at the same rate throughout ontogeny. The distance between epithelial pores in both species and in both canals also increased and at the same rate throughout ontogeny. 


\section{DISCUSSION}

The lateral line canal system of bony fishes is the product of the development of several different tissue types - dermal bone and both the general epithelium (forming pores) and the sensory epithelia composed of sensory hair cells and non-sensory support cells. The lateral line canal pores form during the process of canal morphogenesis and are essential for mechanosensory capabilities. Differences in size and shape of neuromasts within canals and variation in the structure of a canal are thought to be responsible for the functional properties of the lateral line canal system (Denton and Gray, 1988).

Neuromasts are the landmarks needed for the formation of the canal (neuromast-centered canal morphogenesis) and thus the canal pores. Neuromast patterning is the same in both species (Becker, 2013), so it is not surprising that bony pore number and general location are the same among species as well. The six hypotheses concerning the ontogeny of lateral line canal pores were tested (Figure 5) and are discussed below.

Hypothesis 1 stated that the number of pores would decrease as fish size increased in both species. This prediction was based on the initial formation of terminal pores of adjacent canal segments and then the fusion of two terminal pores to form one pore (located between two adjacent neuromasts), thus resulting in a decrease in pore number. This trend was seen in smaller animals, but this hypothesis was not supported when larger animals were considered. The number of bony pores, after initial canal ossification, is set at four per side in each canal, plus the terminal pores of the canal. Complete canal ossification of both SO and MD canals occurs around $24 \mathrm{~mm}$ SL in Tramitichromis and $40 \mathrm{~mm}$ SL in Aulonocara. Fully ossified canals are present at the 
early adult stages (adult coloration) in Tramitichromis, but initial ossification is delayed in Aulonocara (see also Bird and Webb, 2014)

Epithelial pores showed a trend that was different from that found for bony pores. Both species showed an ontogenetic increase in the number of epithelial pores. Early in ontogeny, this is the result of initial pore formation and in larger fish it is likely a result of the branching and proliferation of epithelial pores, especially in the SO canal.

Proliferation of epithelial pores has also been observed in Tilapia, another species of cichlid (Peters, 1973).

Hypothesis 2 stated that bony-pore width would decrease with fish size, but at a faster rate in Tramitichromis than in Aulonocara, which would explain the presence of smaller bony pores in Tramitichromis than in Aulonocara. This hypothesis was formulated based on the fact that Aulonocara has wider canals than Tramitichromis after canal morphogenesis is complete (Bird and Webb, 2014). Widened canals have larger pores, which result from the less complete ossification of the canal roof. CT reconstructions of the mandible and mandibular canal have shown that this is indeed the case (Figure 15). This hypothesis was not supported. Bony pore width increased though ontogeny at the same rate in both species (with the exception of the MD canal of larger Tramitichromis). A possible explanation for this result is that the canals themselves are getting wider as fish get bigger (Tarby and Webb, 2003; Bird and Webb, 2014) and therefore, if the canal is getting wider, it is likely that the pores would follow suit. Hypothesis 3 stated that, like bony-pore width, epithelial-pore width would decrease with fish size, but at the same rate in both species. It is possible (and highly likely) the epithelial pores are under different constraints than the bony pores, and 
therefore may demonstrate different ontogenetic trends. The epithelial pores form first (i.e. at Stage III) before the canal walls and roof have ossified forming a bony pore (Stage IV). Methylene blue stained fish (which show the epithelial pores well) and cleared and stained fish (which show the bony pores well) revealed that the epithelial pores tended to be narrower in width than the bony pores, especially in Aulonocara (Figure 11). The hypothesis that epithelial pores decrease in size was not supported in larvae and younger juveniles (8-19.5 mm SL) where epithelial pore width increased in both species, but the hypothesis was supported in older juveniles (16-59 $\mathrm{mm} \mathrm{SL}$ ) where epithelial-pore width decreased (Figure 11). The fact that bony and epithelial pore widths show a difference in trends suggests that they are subject to different constraints (i.e. bone growth, limited space within the cranium). Finally, the ontogenetic differences in the rate of growth of pores in larvae and early juveniles versus older juveniles could be due to a difference in the methods used to test the early and later stages of development (histology vs. methylene blue) or it could be a true ontogenetic difference that is the result of the way in which pores form.

Hypothesis 4 stated that the ratio of pore length to fish size would be 1:1 throughout ontogeny in both species. To address this, ontogenetic trends in pore length (similar to those for pore width) were analyzed. Bony pore length showed species differences in smaller fish where Aulonocara bony pore length increased with fish size and Tramitichromis bony pore length did not change with fish size. In larger fish, both species showed an increase in bony pore length with fish size. It is possible that bony pore length increases, but when viewed in the context of the whole fish looks like it is decreasing in size due to a faster relative increase in fish length or length of the bone of 
which the pore is associated. This relationship varied depending on the canal (MD or SO) and the size of fish (larvae and early juveniles versus older juveniles and adults). Early in ontogeny, the ratio of pore length to SL in Aulonocara decreased in the MD canal and increased in the SO canal with Tramitichromis having a slope closer to zero in both canals indicating a 1:1 ratio of pore length to standard length. Tramitichromis have a narrow canal morphology and it is possible that since the pores are not as wide as they are in Aulonocara that pore growth is more in the rostro-caudal direction (along the axis of the canal) meaning little to no constraint on pore length.

Hypothesis 5 stated that, like pore width, pore area would decrease through ontogeny in both species with no difference in rate between the two species. The data showed that bony pores increase in area as fish size increases and that the rate of increase is greater in Aulonocara than in Tramitichromis. It is possible that the difference seen between species is because pores in Tramitichromis are getting smaller (relative to fish size) faster than the pores in Aulonocara. Pore area is a function of (calculated from) bony pore length and bony pore width, so both of these parameters need to be looked at to fully understand the ontogeny of pore area. Bony pore width and bony pore length increased through ontogeny in both species. Epithelial pore area showed a difference in rates between the species as well. Aulonocara pore epithelial area increased in larvae and small juveniles (8-19.5 mm SL), whereas the larger juveniles and adults showed no change in epithelial pore size (MD+SO combined). Tramitichromis epithelial pores increased in area early in ontogeny, but then in larger fish (16-59 $\mathrm{mm} \mathrm{SL})$ they decreased in area. This could possibly be explained by the way pores form within the canal. Pores originally form by enclosing between neuromasts. The epithelium encloses before the 
bone forming an epithelial pore within which a bony pore will later ossify. Epithelial pores of Labeotropheus fuelleborni (narrow canal) appear to decrease in size through ontogeny (Webb et al., 2014).

Hypothesis 6 stated that, in contrast to pore width and length, the distance between pores (bony and epithelial) would increase with fish size and at the same rate in both species. It makes sense that if a pore is decreasing in size as the fish gets bigger that the distance between pores would subsequently increase. This hypothesis was partly supported based on the data collected. Throughout ontogeny, both Aulonocara and Tramitichromis showed either an increase in distance between pores or no change. Early in ontogeny (8-19.5 mm SL), there was a species difference such that the distance between bony pores in Tramitichromis increased and Aulonocara showed no change. Later in ontogeny (16-59 $\mathrm{mm} \mathrm{SL}$ ), the distance between bony pores (MD canal) increased in both Aulonocara and Tramitichromis. There are two possible explanations for this result. Either the length of the bony pores is decreasing through ontogeny or the length of the bone (nasal/frontal or dentary/anguloarticular) in which the canal is embedded is increasing at a faster rate than the length of the pores and the canal elongates in concert with the bone. Bony pore length increased with fish size in both Aulonocara and Tramitichromis; therefore it is more likely that the distance between bony pores is due to a faster growth of the fish relative to the pore (see hypothesis 4 data, Table 2). The distance between epithelial pores increased through ontogeny in both species with no significant difference between the species. Even though the epithelial pores are associated with the bony pores, the length of the bone associated with the canal may not necessarily account for the increase in distance between epithelial pores. The rate at which epithelial 
pore length changes was lower in the larger specimens in both species (16-59 mm SL), meaning that the rate of increase in epithelial pore length was lower in older specimens. This most likely accounts for the increase in distance between pores because if epithelial pore length is decreasing this means that the distance between the pores is likely going to increase. Again, there may be more factors that affect this parameter, but this seems to fit the story.

\section{Conclusions}

There are many moving parts that come into play when analyzing the ontogeny of the cranial lateral line system. One parameter cannot be considered without looking at another because the system itself is highly integrated (modularity; Bird and Webb, 2014). For instance, if pore width is considered, it only makes sense to look at canal width because the pores are a component of the canal itself. The same can be said when looking at pore length, but this is limited because some canal roof must remain to maintain the structural integrity of the canal and thus its function. Pore area was determined through a calculation of these two values, each divided by 2 , and then multiplied by $\pi$, which means that pore area is a function of pore width and pore length. The inter-pore distance is related to both pore length and length of the individual bones; therefore, both need to be considered when analyzing this parameter.

This study found that some parameters differ in ontogenetic trends depending on the life history stage examined (e.g., larvae and early juveniles versus older juveniles and small adults). In addition, this study used different methods in order to analyze the pores histology in larvae and small juveniles (8-19.5 mm SL) and either methylene blue 
(epithelial pores) or cleared and stained individuals in larger juveniles and adults (16-59 $\mathrm{mm}$ SL). Since there is a difference in the method used to prepare the specimens, there are two possible explanations for differences in trends throughout ontogeny. One explanation could be a developmental difference meaning that after the fish reaches a certain size some of the constraints within the fish or canal change and result in a change in one or more of the measured parameters. The second explanation has to do with the methodology used. The smaller fish were prepared histologically, while the larger fish were stained with methylene blue and then subsequently cleared and stained, so there are possible preparation artifacts that need to be considered. It has been said that because of the way histological specimens are prepared, shrinkage may be a factor. If the paraffin block containing the tissue is not sectioned at the right angle (e.g., 90 degrees to the axis of the fish for transverse sections), it could affect the measurements (on the scale of micrometers) being made on those sections. The techniques used on the larger specimens are much simpler to complete, but may not be as precise (on the scale of a micrometer)

Another artifact that needs to be considered is that the fish used for this study were reared in the laboratory and may not be subject to the same environmental constraints or selective pressures as fishes in their natural environment. Lab-reared fish lack predators and do not have to forage or compete for resources. This may have a direct epigenetic effect on canal pore development through exogenous factors such as lack of water movement. It is thought that pores (especially in Aulonocara) are aiding in the sensing capabilities of the fish and therefore aiding in the search for prey (Schwalbe et al., 2012, 2014). The lack of these environmental factors in the lab could possibly affect pore development as well as other aspects of canal and neuromast development. Since 
there has been no active research on the role of the lateral line system in feeding in cichlids in the wild, a comparison is not possible, but the fact that these cichlids are labreared could be an explanation for the amount of variability seen in the data. The amount of variability could also be seen in the wild. Variability is expected in all organisms, but the extent to which variability occurred here is unknown.

In order for pores to change and develop over time there must be guiding mechanisms and constraints on their formation. These constraints can come in many different forms, but the most obvious would be if there were no constraints on development, all the canals and pores would be the same. In this case, the two species of cichlids differ in the behaviors and sensory inputs that they use to seek out prey (Schwalbe et al., 2012). There also must be developmental constraints on the canal itself. The bone in which the canals are found must bear some sort of constraint in order for the canal and jaw or head in general to function as one and not interrupt other developmental or functional aspects of the head. The size and shape of the pores are at the mercy of the canals. In the wild it is possible there are more selective pressures present on the fish that may be absent in the lab, such as competition and predation, while in the lab a fish is more likely to be affected by disease. Pore development and morphology are more likely to be a combination of developmental constraints and selective pressures in the lab.

When looking at function of the lateral line system, one must consider multiple factors including neuromast size (size of sensory strip containing hair cells), type of canal system (morphology), and number and size of canal pores. The size, shape, and area of the pores as well as the distance between pores are all likely to have functional implications for the mechanosensory capabilities of the fish. Both bony and epithelial 
pore area are important functionally for different reasons. Flow in the lateral line canals depends on pressure differences between neighboring canal pores, which is affected by the distance between the pores (Kalmijn, 1988). Epithelial pores link the interior fluid of the canal to the environment and in widened canals the size of the bony pore determines the size of the epithelial tympanum above the bony pore, which are thought to move with pressure fluctuations and water disturbances (Bleckmann and Zelick, 2009) and thus causes the water to move within the canal, which is sensed by the cupula of the canal neuromast.

The results of this project are the first of their kind. Until now, the development of pores was an unexplored aspect of the lateral line system. These results showed interesting ontogenetic trends in pore length, width, and area, which in some cases change from the larval to the juvenile stage (Figure 16). The way in which a canal develops is not straightforward and the mechanisms behind the development are still not completely understood. The two cichlid species have obvious differences in the way in which the pores develop and grow as the fish grows and these results show interesting trends that can be considered as a starting point for future studies. 
Table 1: Number of bony and epithelial pores (right+left, SO+MD combined) in larval and juvenile Aulonocara and Tramitichromis (8-59 mm SL, standard length). All specimens were prepared histologically, but those marked with * were methylene blue stained and subsequently cleared and stained.

\begin{tabular}{|c|c|c|c|c|c|}
\hline \multicolumn{3}{|c|}{ Aulonocara } & \multicolumn{3}{|c|}{ Tramitichromis } \\
\hline $\begin{array}{l}\text { Fish Size } \\
(\mathrm{mm})\end{array}$ & \# bony pores & $\begin{array}{l}\text { \# epithelial } \\
\text { pores }\end{array}$ & $\begin{array}{l}\text { Fish Size } \\
(\mathrm{mm})\end{array}$ & \# bony pores & $\begin{array}{c}\text { \# epithelial } \\
\text { pores }\end{array}$ \\
\hline 11 & 0 & 2 & 8 & 0 & 2 \\
\hline 11 & 1 & 6 & 9 & 1 & 6 \\
\hline 11.5 & 1 & 3 & 9 & 1 & 5 \\
\hline 12 & 5 & 2 & 9 & 2 & 6 \\
\hline 13 & 2 & 4 & 9 & 0 & 4 \\
\hline 13 & 0 & 6 & 10 & 2 & 5 \\
\hline 13 & 2 & 7 & 10 & 2 & 2 \\
\hline 14 & 4 & 8 & 11 & 8 & 9 \\
\hline 15 & 2 & 3 & 11.5 & 7 & 7 \\
\hline $16^{*}$ & 12 & 14 & 12 & 4 & 6 \\
\hline 18 & 6 & 7 & 13 & 8 & 9 \\
\hline 18 & 5 & 5 & 13 & 9 & 12 \\
\hline 18 & 7 & 8 & 13.5 & 8 & 9 \\
\hline $18^{*}$ & 7 & 13 & 15 & 9 & 10 \\
\hline 18.5 & 10 & 11 & 15 & 9 & 9 \\
\hline 19 & 7 & 9 & $16.5^{*}$ & 14 & 13 \\
\hline 19.5 & 10 & 10 & 17 & 10 & 10 \\
\hline $20 *$ & 10 & 13 & $19.5^{*}$ & 10 & 15 \\
\hline $21.5^{*}$ & 7 & 12 & $20.5^{*}$ & 12 & 17 \\
\hline $23^{*}$ & 12 & 14 & $22 *$ & 12 & 14 \\
\hline $25^{*}$ & 11 & 16 & $24^{*}$ & 16 & 17 \\
\hline $28 *$ & 7 & 13 & $26^{*}$ & 13 & 16 \\
\hline $30 *$ & 9 & 13 & $29 *$ & 15 & 16 \\
\hline $32.5^{*}$ & 12 & 16 & $32 *$ & 12 & 16 \\
\hline $33.5 *$ & 13 & 16 & $35^{*}$ & 11 & 16 \\
\hline $35^{*}$ & 10 & 14 & $36^{*}$ & 5 & 9 \\
\hline $37.5^{*}$ & 11 & 16 & $38 *$ & 10 & 18 \\
\hline $40 *$ & 16 & 20 & $40 *$ & 12 & 21 \\
\hline $41.5^{*}$ & 7 & 17 & $43^{*}$ & 12 & 24 \\
\hline $43^{*}$ & 14 & 21 & $45^{*}$ & 13 & 21 \\
\hline $45^{*}$ & 16 & 21 & $46^{*}$ & 12 & 20 \\
\hline $47.5^{*}$ & 8 & 19 & $48^{*}$ & 15 & 23 \\
\hline $52.5^{*}$ & 6 & 14 & $50 *$ & 13 & 18 \\
\hline $59 *$ & 12 & 17 & $52.5^{*}$ & 12 & 22 \\
\hline & & & $55^{*}$ & 15 & 27 \\
\hline
\end{tabular}


Table 2: Summary ANOVA statistics for pore parameters vs. fish length (mm SL) for Aulonocara (AU) and Tramitichromis (TRA), using MD and SO data combined (COMB) and MD and SO data considered separately.

\begin{tabular}{|c|c|c|c|c|c|}
\hline & Canal & $\mathbf{N}$ & Regression & $\mathbf{R}^{2}$ & $P$ \\
\hline \multicolumn{6}{|c|}{ Bony Pore Area - $A U$} \\
\hline \multirow[t]{3}{*}{ Histology } & COMB. & 52 & $\mathrm{y}=10098.86^{*} \mathrm{x}-113488.1$ & 0.17 & 0.0023 \\
\hline & MD & 12 & $y=283.57 * x+91001.27$ & 0.00007 & 0.9794 \\
\hline & SO & 38 & $y=9215.97 * x-106424.6$ & 0.16 & 0.0122 \\
\hline \multirow[t]{3}{*}{$C \& S$} & COMB. & 111 & $\mathrm{y}=5736.05 * \mathrm{x}-38898.77$ & 0.50 & $<.0001$ \\
\hline & MD & 44 & $\mathrm{y}=7518.21 * \mathrm{x}-72138.83$ & 0.60 & $<.0001$ \\
\hline & SO & 67 & $\mathrm{y}=4325.93 * \mathrm{x}-11251.33$ & 0.51 & $<.0001$ \\
\hline \multicolumn{6}{|c|}{ Bony Pore Area - $T R A$} \\
\hline \multirow[t]{3}{*}{ Histology } & COMB. & 74 & $y=1213.14 * x-5992.65$ & 0.07 & 0.0215 \\
\hline & MD & 12 & $y=1421.37^{*} x-2084.23$ & 0.02 & 0.6388 \\
\hline & $\mathrm{SO}$ & 62 & $y=981.93^{*} x-4272.9$ & 0.10 & 0.0119 \\
\hline \multirow[t]{3}{*}{$\mathrm{C} \& \mathrm{~S}$} & COMB. & 126 & $y=1684.69 * x-12228.87$ & 0.51 & $<.0001$ \\
\hline & MD & 64 & $y=1590.92 * x-4926.47$ & 0.51 & $<.0001$ \\
\hline & $\mathrm{SO}$ & 62 & $y=1776.79 * x-19574.56$ & 0.53 & $<.0001$ \\
\hline \multicolumn{6}{|c|}{ Epithelial Pore Area - $A U$} \\
\hline \multirow[t]{3}{*}{ Histology } & COMB. & 83 & $y=2834.00 * x-26467.97$ & 0.07 & 0.0135 \\
\hline & MD & 33 & $y=2186.95 * x-18794.18$ & 0.21 & 0.0093 \\
\hline & SO & 50 & $y=3178.77^{*} x-30286.41$ & 0.07 & 0.0718 \\
\hline \multirow[t]{3}{*}{ MB } & COMB & 325 & $y=241.12 * x+22228.12$ & 0.007 & 0.1448 \\
\hline & MD & 155 & $y=863.28 * x+12472.50$ & 0.05 & 0.0046 \\
\hline & $\mathrm{SO}$ & 170 & $y=-321.53^{*} x+30969.70$ & 0.07 & 0.0005 \\
\hline \multicolumn{6}{|c|}{ Epithelial Pore Area - TRA } \\
\hline \multirow[t]{3}{*}{ Histology } & COMB. & 108 & $\mathrm{y}=248.44 * x-434.07$ & 0.16 & $<0.0001$ \\
\hline & MD & 18 & $y=454.64 * x-2708.17$ & 0.29 & 0.0224 \\
\hline & $\mathrm{SO}$ & 90 & $y=26.97 * x+200.81$ & 0.12 & 0.001 \\
\hline \multirow[t]{3}{*}{ MB } & COMB. & 371 & $y=-325.30 * x+25534.7$ & 0.05 & $<.0001$ \\
\hline & MD & 171 & $y=-200.41 * x+24064.05$ & 0.01 & 0.1226 \\
\hline & SO & 201 & $y=-407.87 * x+25996.42$ & 0.158 & $<.0001$ \\
\hline \multicolumn{6}{|c|}{ Log Bony Pore Width - $A U$} \\
\hline \multirow[t]{3}{*}{ Histology } & COMB. & 50 & $\log y=0.13 * x+2.81$ & 0.33 & $<.0001$ \\
\hline & MD & 12 & $\log y=0.05 * x+4.39$ & 0.08 & 0.3717 \\
\hline & $\mathrm{SO}$ & 38 & $\log y=0.11 * x+2.91$ & 0.3 & 0.0004 \\
\hline \multirow[t]{3}{*}{ C\&S } & COMB. & 112 & $\log y=0.02 * x+5.25$ & 0.42 & $<.0001$ \\
\hline & MD & 44 & $\log y=0.02 * x+5.27$ & 0.62 & $<.0001$ \\
\hline & $\mathrm{SO}$ & 68 & $\log y=0.02 * x+5.28$ & 0.36 & $<.0001$ \\
\hline
\end{tabular}




\begin{tabular}{|c|c|c|c|c|c|}
\hline \multicolumn{6}{|c|}{ Log Bony Pore Width - TRA } \\
\hline \multirow[t]{3}{*}{ Histology } & COMB. & 70 & $\log y=0.07 * x+3.28$ & 0.09 & 0.0109 \\
\hline & $\mathrm{MD}$ & 12 & $\log y=-0.13 * x+6.31$ & 0.24 & 0.1075 \\
\hline & SO & 58 & $\log y=0.09 * x+2.94$ & 0.17 & 0.0011 \\
\hline \multirow[t]{3}{*}{ C\&S } & COMB. & 125 & $\log y=0.02 * x+4.61$ & 0.39 & $<.0001$ \\
\hline & $\mathrm{MD}$ & 62 & $\log y=0.01 * x+4.79$ & 0.35 & $<.0001$ \\
\hline & SO & 63 & $\log y=0.02 * x+4.44$ & 0.46 & $<.0001$ \\
\hline \multicolumn{6}{|c|}{ Log Epithelial Pore Width - $A U$} \\
\hline \multirow[t]{3}{*}{ Histology } & COMB. & 85 & $\log y=0.11 * x+2.65$ & 0.36 & $<.0001$ \\
\hline & $\mathrm{MD}$ & 33 & $\log y=0.10 * x+3.00$ & 0.31 & 0.0008 \\
\hline & SO & 52 & $\log y=0.11 * x+2.55$ & 0.37 & $<.0001$ \\
\hline \multirow[t]{3}{*}{ MB } & COMB. & 340 & $\log y=-0.01 * x+5.11$ & 0.01 & $\mathbf{0 . 0 3 5 4}$ \\
\hline & $\mathrm{MD}$ & 162 & $\log y=0.0004 * x+5.02$ & 0.00008 & 0.9093 \\
\hline & SO & 178 & $\log y=-0.01 * x+5.19$ & 0.07 & 0.0005 \\
\hline \multicolumn{6}{|c|}{ Log Epithelial Pore Width - TRA } \\
\hline \multirow[t]{3}{*}{ Histology } & COMB. & 107 & $\log y=0.14 * x+1.96$ & 0.39 & $<.0001$ \\
\hline & $\mathrm{MD}$ & 18 & $\log y=0.08 * x+2.88$ & 0.34 & 0.0106 \\
\hline & SO & 89 & $\log y=0.14 * x+1.96$ & 0.36 & $<.0001$ \\
\hline \multirow[t]{3}{*}{ MB } & COMB. & 370 & $\log y=-0.01 * x+5.04$ & 0.88 & $<.0001$ \\
\hline & MD & 168 & $\log y=-0.01 * x+4.81$ & 0.01 & 0.12 \\
\hline & SO & 202 & $\log y=-0.02 * x+5.20$ & 0.18 & $<.0001$ \\
\hline \multicolumn{6}{|c|}{ Log Bony Pore Length - $A U$} \\
\hline \multirow[t]{3}{*}{ Histology } & COMB. & 53 & $\log y=0.11 * x+3.80$ & 0.11 & 0.0146 \\
\hline & MD & 12 & $\log y=-0.11 * x+8.10$ & 0.04 & 0.5179 \\
\hline & SO & 41 & $\log y=0.10 * x+3.76$ & 0.13 & 0.0207 \\
\hline \multirow[t]{3}{*}{$\mathrm{C} \& \mathrm{~S}$} & COMB. & 11 & $\log y=0.02 * x+5.44$ & 0.43 & $<.0001$ \\
\hline & $\mathrm{MD}$ & 44 & $\log y=0.02 * x+5.35$ & 0.62 & $<.0001$ \\
\hline & SO & 67 & $\log y=0.02 * x+5.50$ & 0.33 & $<.0001$ \\
\hline \multicolumn{6}{|c|}{ Log Bony Pore Length - TRA } \\
\hline \multirow[t]{3}{*}{ Histology } & COMB. & 70 & $\log y=0.04 * x+4.41$ & 0.03 & 0.1364 \\
\hline & MD & 12 & $\log y=0.07 * x+4.26$ & 0.06 & 0.4515 \\
\hline & SO & 58 & $\log y=0.03 * x+4.51$ & 0.02 & 0.3007 \\
\hline \multirow[t]{3}{*}{$\mathrm{C} \& \mathrm{~S}$} & COMB. & 125 & $\log y=0.02 * x+4.95$ & 0.36 & $<.0001$ \\
\hline & MD & 62 & $\log y=0.02 * x+5.10$ & 0.51 & $<.0001$ \\
\hline & SO & 63 & $\log y=0.02 * x+4.83$ & 0.38 & $<.0001$ \\
\hline \multicolumn{6}{|c|}{ Log Epithelial Pore Length - $A U$} \\
\hline \multirow[t]{3}{*}{ Histology } & COMB. & 85 & $\log y=0.03 * x+4.58$ & 0.02 & 0.1485 \\
\hline & $\mathrm{MD}$ & 33 & $\log y=0.05 * x+4.37$ & 0.09 & 0.0966 \\
\hline & SO & 52 & $\log y=0.02 * x+4.72$ & 0.01 & 0.517 \\
\hline \multirow[t]{3}{*}{ MB } & COMB. & 340 & $\log y=-0.004 * x+5.33$ & 0.01 & 0.1536 \\
\hline & $\mathrm{MD}$ & 162 & $\log y=0.01 * x+5.12$ & 0.03 & 0.0276 \\
\hline & SO & 178 & $\log y=-0.01 * x+5.52$ & 0.13 & $<.0001$ \\
\hline
\end{tabular}




\begin{tabular}{|c|c|c|c|c|c|}
\hline \multicolumn{6}{|c|}{ Log Epithelial Pore Length - TRA } \\
\hline \multirow[t]{3}{*}{ Histology } & COMB. & 109 & $\log y=-0.003 * x+4.19$ & 0.0005 & 0.8195 \\
\hline & MD & 18 & $\log y=0.06 * x+3.40$ & 0.20 & 0.0621 \\
\hline & SO & 91 & $\log y=-0.02 * x+4.32$ & 0.01 & 0.3127 \\
\hline \multirow[t]{3}{*}{ MB } & COMB. & 370 & $\log y=-0.02 * x+5.32$ & 0.12 & $<.0001$ \\
\hline & MD & 168 & $\log y=-0.01 * x+5.24$ & 0.04 & 0.011 \\
\hline & SO & 202 & $\log y=-0.02 * x+5.30$ & 0.23 & $<.0001$ \\
\hline \multicolumn{6}{|c|}{ Ratio of Bony Pore Length/SL - $A U$} \\
\hline \multirow[t]{3}{*}{ Histology } & COMB. & 53 & $y=0.96 * x+5.10$ & 0.02 & 0.3097 \\
\hline & MD & 12 & $y=-4.05 * x+105.17$ & 0.12 & 0.274 \\
\hline & SO & 41 & $y=0.90 * x+3.72$ & 0.02 & 0.3506 \\
\hline \multirow[t]{3}{*}{$\mathrm{C} \& \mathrm{~S}$} & COMB. & 111 & $y=-0.16^{*} x+19.92$ & 0.26 & $<.0001$ \\
\hline & MD & 44 & $y=-0.10 * x+17.96$ & 0.17 & 0.0051 \\
\hline & SO & 67 & $y=-0.19^{*} x+21.08$ & 0.31 & $<.0001$ \\
\hline \multicolumn{6}{|c|}{ Ratio of Bony Pore Length/SL - TRA } \\
\hline \multirow[t]{3}{*}{ Histology } & COMB. & 70 & $y=-0.17 * x+14.45$ & 0.004 & 0.6113 \\
\hline & MD & 12 & $y=0.53 * x+7.43$ & 0.01 & 0.7233 \\
\hline & SO & 58 & $y=-0.37 * x+16.40$ & 0.02 & 0.2564 \\
\hline \multirow[t]{3}{*}{$\mathrm{C} \& \mathrm{~S}$} & COMB. & 125 & $y=-0.11 * x+12.21$ & 0.24 & $<.0001$ \\
\hline & MD & 62 & $y=-0.12 * x+13.74$ & 0.36 & $<.0001$ \\
\hline & SO & 63 & $y=-0.11 * x+10.93$ & 0.26 & $<.0001$ \\
\hline \multicolumn{6}{|c|}{ Ratio of Epithelial Pore Length/SL - $A U$} \\
\hline \multirow[t]{3}{*}{ Histology } & COMB. & 85 & $y=-0.31 * x+17.09$ & 0.03 & 0.3818 \\
\hline & MD & 33 & $y=-0.22 * x+14.99$ & 0.09 & 0.4469 \\
\hline & SO & 52 & $y=-0.32 * x+17.67$ & 0.008 & 0.5494 \\
\hline \multirow[t]{3}{*}{ MB } & COMB. & 340 & $y=-0.16^{*} x+10.55$ & 0.32 & $<.0001$ \\
\hline & MD & 162 & $y=-0.15^{*} x+10.99$ & 0.21 & $<.0001$ \\
\hline & SO & 178 & $y=-0.16^{*} x+10.14$ & 0.55 & $<.0001$ \\
\hline \multicolumn{6}{|c|}{ Ratio of Epithelial Pore Length/SL - TRA } \\
\hline \multirow[t]{3}{*}{ Histology } & COMB. & 109 & $y=-0.44 * x+11.11$ & 0.0005 & $<.0001$ \\
\hline & MD & 18 & $y=-0.04 * x+6.00$ & 0.2 & 0.8041 \\
\hline & SO & 89 & $y=-0.49 * x+11.67$ & 0.01 & $<.0001$ \\
\hline \multirow[t]{3}{*}{ MB } & COMB. & 370 & $y=-0.16^{*} x+9.38$ & 0.44 & $<.0001$ \\
\hline & MD & 168 & $y=-0.12 * x+8.08$ & 0.36 & $<.0001$ \\
\hline & $\mathrm{SO}$ & 202 & $y=-0.18^{*} x+10.43$ & 0.57 & $<.0001$ \\
\hline \multicolumn{6}{|c|}{ Distance Between Bony Pores - $A U$} \\
\hline \multirow[t]{3}{*}{ Histology } & COMB. & 22 & $y=-0.13 * x+7.63$ & 0.05 & 0.3086 \\
\hline & MD & 3 & --- & & \\
\hline & SO & 19 & $y=-0.04 * x+6.24$ & 0.01 & 0.716 \\
\hline \multirow[t]{2}{*}{$\mathrm{C} \& \mathrm{~S}$ (no data for $\mathrm{SO}$ ) } & COMB. & 55 & $y=0.03 * x+4.12$ & 0.23 & 0.0002 \\
\hline & MD & 55 & $y=0.03 * x+4.12$ & 0.23 & 0.0002 \\
\hline
\end{tabular}




\begin{tabular}{|c|c|c|c|c|c|}
\hline \multicolumn{6}{|c|}{ Distance Between Bony Pores - Tramitichromis } \\
\hline \multirow[t]{3}{*}{ Histology } & COMB. & 37 & $\mathrm{y}=0.13 * \mathrm{x}+3.47$ & 0.25 & 0.0017 \\
\hline & MD & 1 & --- & & \\
\hline & SO & 36 & $\mathrm{y}=0.1393272 * \mathrm{x}+3.37$ & 0.33 & 0.0003 \\
\hline \multirow[t]{3}{*}{ C\&S } & COMB. & 84 & $\mathrm{y}=0.04 * x+4.61$ & 0.44 & $<.0001$ \\
\hline & MD & 84 & $y=0.04 * x+4.61$ & 0.44 & $<.0001$ \\
\hline & SO & 0 & --- & & \\
\hline \multicolumn{6}{|c|}{ Log Distance Between Epithelial Pores - Aulonocara } \\
\hline \multirow[t]{3}{*}{ Histology } & COMB. & 36 & $\log y=0.12 * x+3.92$ & 0.29 & 0.0007 \\
\hline & MD & 13 & $\log y=0.09 * x+4.18$ & 0.11 & 0.2578 \\
\hline & SO & 23 & $\log y=0.14 * x+3.68$ & 0.53 & $<.0001$ \\
\hline \multirow[t]{3}{*}{ MB } & COMB. & 258 & $\log y=0.03 * x+5.65$ & 0.29 & $<.0001$ \\
\hline & MD & 131 & $\log y=0.04 * x+5.24$ & 0.33 & $<.0001$ \\
\hline & SO & 127 & $\log y=0.03 * x+6.03$ & 0.48 & $<.0001$ \\
\hline \multicolumn{6}{|c|}{ Log Distance Between Epithelial Pores - Tramitichromis } \\
\hline \multirow[t]{3}{*}{ Histology } & COMB. & 76 & $\log y=0.09 * x+4.5418202$ & 0.49 & $<.0001$ \\
\hline & MD & 5 & --- & & \\
\hline & SO & 71 & $\log y=0.10 * x+4.50$ & 0.53 & $<.0001$ \\
\hline \multirow[t]{3}{*}{ MB } & COMB. & 241 & $\log y=0.03 * x+5.85$ & 0.26 & $<.0001$ \\
\hline & MD & 130 & $\log y=0.03 * x+5.41$ & 0.36 & $<.0001$ \\
\hline & SO & 110 & $\log y=0.03 * x+6.28$ & 0.37 & $<.0001$ \\
\hline
\end{tabular}


Table 3: Summary ANCOVA statistics for comparison of slopes between species (Aulonocara and Tramitichromis), for each pore parameter vs. fish length. Data was analyzed for MD and SO combined (COMB) and for MD and SO considered separately. T-test results are presented for analyses with non-significant $P$ values. See also Figures 11, 12, 13 and 14.

\begin{tabular}{|c|c|c|c|c|c|}
\hline & Canal & $\mathrm{N}$ & $\mathrm{R}^{2}$ & Interaction $P$-value & t-test Result \\
\hline \multicolumn{6}{|c|}{ Bony Pore Area } \\
\hline \multirow[t]{3}{*}{ Histology } & COMB. & 126 & 0.37 & 0.0022 & \\
\hline & MD & 24 & 0.54 & 0.9107 & $\mathrm{AU}>\mathrm{TRA}$ \\
\hline & $\mathrm{SO}$ & 102 & 0.31 & 0.0061 & \\
\hline \multirow[t]{3}{*}{$C \& S$} & COMB. & 237 & 0.7 & $<0.0001$ & \\
\hline & MD & 108 & 0.77 & $<0.0001$ & \\
\hline & $\mathrm{SO}$ & 129 & 0.72 & $<0.0001$ & \\
\hline \multicolumn{6}{|c|}{ Epithelial Pore Area } \\
\hline \multirow[t]{3}{*}{ Histology } & COMB. & 187 & 0.19 & 0.0206 & \\
\hline & MD & 51 & 0.44 & 0.2427 & $\mathrm{AU}>\mathrm{TRA}$ \\
\hline & $\mathrm{SO}$ & 136 & 0.16 & 0.0409 & \\
\hline \multirow[t]{3}{*}{ MB } & COMB. & 697 & 0.12 & 0.0008 & \\
\hline & MD & 326 & 0.18 & 0.0007 & \\
\hline & $\mathrm{SO}$ & 371 & 0.21 & 0.4357 & $\mathrm{AU}>\mathrm{TRA}$ \\
\hline \multicolumn{6}{|c|}{ Log Bony Pore Width } \\
\hline \multirow[t]{3}{*}{ Histology } & COMB. & 120 & 0.45 & 0.1436 & $\mathrm{AU}>\mathrm{TRA}$ \\
\hline & MD & 24 & 0.65 & 0.0821 & $\mathrm{AU}>\mathrm{TRA}$ \\
\hline & $\mathrm{SO}$ & 96 & 0.43 & 0.5864 & $\mathrm{AU}>\mathrm{TRA}$ \\
\hline \multirow[t]{3}{*}{$\mathrm{C} \& \mathrm{~S}$} & COMB. & 237 & 0.67 & 0.8464 & $\mathrm{AU}>\mathrm{TRA}$ \\
\hline & MD & 106 & 0.81 & 0.0136 & \\
\hline & $\mathrm{SO}$ & 131 & 0.62 & 0.0544 & $\mathrm{AU}>\mathrm{TRA}$ \\
\hline \multicolumn{6}{|c|}{ Log Epithelial Pore Width } \\
\hline \multirow[t]{3}{*}{ Histology } & COMB. & 192 & 0.54 & 0.2029 & $\mathrm{AU}>\mathrm{TRA}$ \\
\hline & MD & 51 & 0.5 & 0.8332 & $\mathrm{AU}>\mathrm{TRA}$ \\
\hline & $\mathrm{SO}$ & 141 & 0.5 & 0.3586 & $\mathrm{AU}>\mathrm{TRA}$ \\
\hline \multirow[t]{3}{*}{ MB } & COMB. & 710 & 0.18 & 0.0077 & \\
\hline & MD & 330 & 0.14 & 0.2478 & $\mathrm{AU}>\mathrm{TRA}$ \\
\hline & SO & 380 & 0.25 & 0.0187 & \\
\hline \multicolumn{6}{|c|}{ Log Bony Pore Length } \\
\hline \multirow[t]{3}{*}{ Histology } & COMB. & 123 & 0.28 & 0.1691 & $\mathrm{AU}>\mathrm{TRA}$ \\
\hline & MD & 24 & 0.38 & 0.328 & $\mathrm{AU}>\mathrm{TRA}$ \\
\hline & SO & 99 & 0.26 & 0.1373 & $\mathrm{AU}>\mathrm{TRA}$ \\
\hline \multirow[t]{3}{*}{$\mathrm{C} \& \mathrm{~S}$} & COMB. & 236 & 0.62 & 0.5417 & $\mathrm{AU}>\mathrm{TRA}$ \\
\hline & MD & 106 & 0.69 & 0.189 & $\mathrm{AU}>\mathrm{TRA}$ \\
\hline & $\mathrm{SO}$ & 130 & 0.68 & 0.8497 & $\mathrm{AU}>\mathrm{TRA}$ \\
\hline
\end{tabular}




\begin{tabular}{|c|c|c|c|c|c|}
\hline \multicolumn{6}{|c|}{ Log Epithelial Pore Length } \\
\hline \multirow[t]{3}{*}{ Histology } & COMB. & 194 & 0.48 & 0.1835 & $\mathrm{AU}>\mathrm{TRA}$ \\
\hline & MD & 51 & 0.58 & 0.7654 & $\mathrm{AU}>\mathrm{TRA}$ \\
\hline & $\mathrm{SO}$ & 143 & 0.43 & 0.2459 & $\mathrm{AU}>\mathrm{TRA}$ \\
\hline \multirow[t]{3}{*}{ MB } & COMB. & 710 & 0.22 & 0.0003 & \\
\hline & MD & 330 & 0.2 & 0.0008 & \\
\hline & $\mathrm{SO}$ & 380 & 0.34 & 0.1478 & $\mathrm{AU}>\mathrm{TRA}$ \\
\hline \multicolumn{6}{|c|}{ Ratio of Bony Pore Length to SL } \\
\hline \multirow[t]{3}{*}{ Histology } & COMB. & 123 & 0.15 & 0.2237 & $\mathrm{AU}>\mathrm{TRA}$ \\
\hline & MD & 24 & 0.34 & 0.2103 & $\mathrm{AU}>\mathrm{TRA}$ \\
\hline & $\mathrm{SO}$ & 99 & 0.12 & 0.1717 & $\mathrm{AU}>\mathrm{TRA}$ \\
\hline \multirow[t]{3}{*}{$C \& S$} & COMB. & 236 & 0.6 & 0.1059 & $\mathrm{AU}>\mathrm{TRA}$ \\
\hline & MD & 106 & 0.59 & 0.7334 & $\mathrm{AU}>\mathrm{TRA}$ \\
\hline & $\mathrm{SO}$ & 130 & 0.68 & 0.0476 & \\
\hline \multicolumn{6}{|c|}{ Ratio of Epithelial Pore Length to SL } \\
\hline \multirow[t]{3}{*}{ Histology } & COMB. & 194 & 0.21 & 0.701 & $\mathrm{AU}>\mathrm{TRA}$ \\
\hline & MD & 51 & 0.4 & 0.7653 & $\mathrm{AU}>\mathrm{TRA}$ \\
\hline & $\mathrm{SO}$ & 143 & 0.19 & 0.696 & $\mathrm{AU}>\mathrm{TRA}$ \\
\hline \multirow[t]{3}{*}{ MB } & COMB. & 710 & 0.44 & 0.5218 & $\mathrm{AU}>\mathrm{TRA}$ \\
\hline & MD & 330 & 0.38 & 0.1358 & $\mathrm{AU}>\mathrm{TRA}$ \\
\hline & $\mathrm{SO}$ & 380 & 0.6 & 0.1657 & $\mathrm{AU}>\mathrm{TRA}$ \\
\hline \multicolumn{6}{|c|}{ Distance Between Bony Pores } \\
\hline \multirow[t]{3}{*}{ Histology } & COMB. & 59 & 0.13 & 0.0913 & $\mathrm{AU}=\mathrm{TRA}$ \\
\hline & MD & 4 & & $\mathrm{x}$ & \\
\hline & $\mathrm{SO}$ & 55 & 0.21 & 0.2859 & $\mathrm{AU}=\mathrm{TRA}$ \\
\hline \multirow[t]{3}{*}{$C \& S$} & COMB. & 139 & 0.61 & 0.1142 & $\mathrm{AU}>\mathrm{TRA}$ \\
\hline & MD & 139 & 0.61 & 0.1142 & $\mathrm{AU}>\mathrm{TRA}$ \\
\hline & $\mathrm{SO}$ & 0 & & $\mathrm{x}$ & \\
\hline \multicolumn{6}{|c|}{ Log Distance Between Epithelial Pores } \\
\hline \multirow[t]{3}{*}{ Histology } & COMB. & 112 & 0.39 & 0.346 & TRA $>$ AU \\
\hline & MD & 18 & 0.12 & 0.7249 & $\mathrm{AU}=\mathrm{TRA}$ \\
\hline & SO & 94 & 0.58 & 0.0683 & TRA $>$ AU \\
\hline \multirow[t]{3}{*}{ MB } & COMB. & 499 & 0.28 & 0.2288 & $\mathrm{AU}=\mathrm{TRA}$ \\
\hline & MD & 261 & 0.35 & 0.5672 & $\mathrm{AU}=\mathrm{TRA}$ \\
\hline & $\mathrm{SO}$ & 237 & 0.43 & 0.1076 & $\mathrm{AU}=\mathrm{TRA}$ \\
\hline
\end{tabular}


A Superficial Neuromast

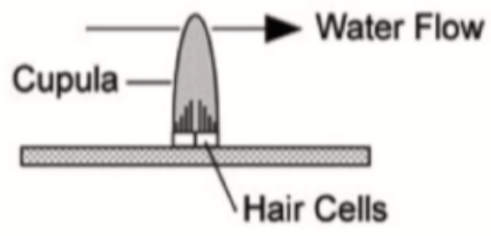

B

Canal Neuromast

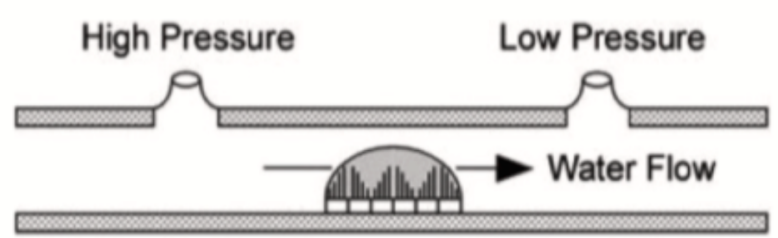

Figure 1: Schematic diagram of (A) a superficial and (B) a canal neuromast. (from Mogdans and Bleckmann, 2012 as redrawn from Coombs and Montgomery, 1999). In A, water flow passes over the cupula of the neuromast sitting on the skin. In B, the water enters the canal and flows from an area (pore) of high pressure to an area (pore) of low pressure. 


\section{A}
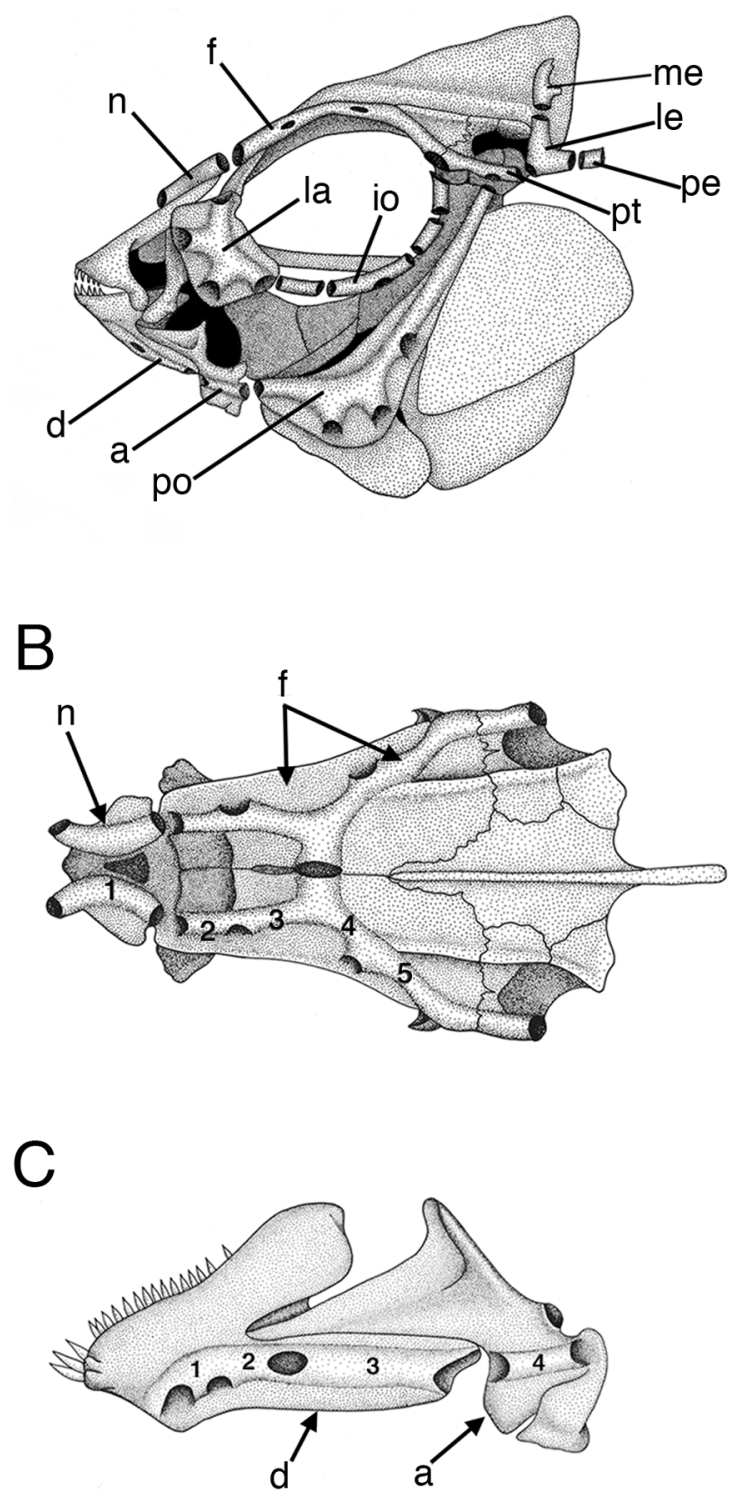

Figure 2: Drawing of skull of an adult convict cichlid (Amatitlania nigrofasciata) from a cleared and stained specimen showing the pored lateral line canals embedded in dermal bones. A) Lateral view showing supraorbital canal within the nasal (n) and frontal (f) bones, mandibular canal within the dentary (d) and Angulo-articular (a) bones, infraorbital canal (io), and pre-opercular (po) canal. B) Dorsal view showing the supraorbital canal, with numbers indicating where canal neuromasts are located. C) Lateral view of the mandibular canal with numbers indicating where canal neuromasts are located. (From Webb, 2014b) 
A

St. I

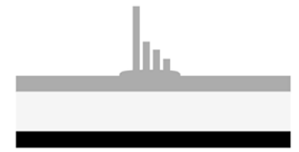

St. Ila

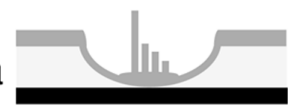

St. IIb

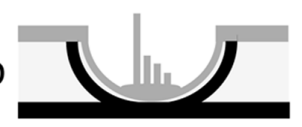

St. III

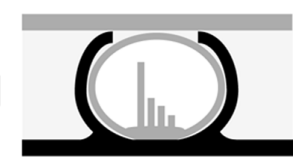

St. IV

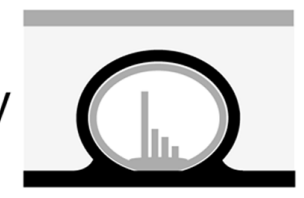

B

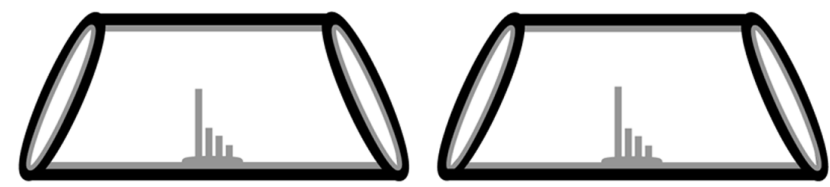

C

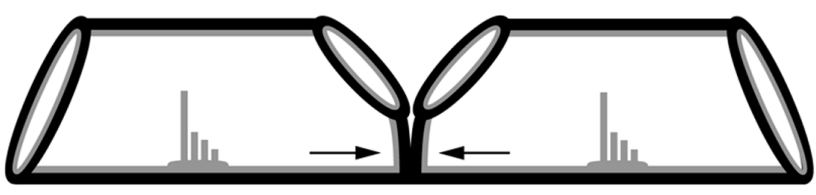

$\mathrm{D}$

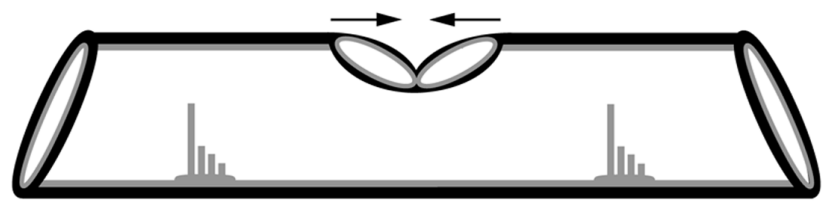

$\mathrm{E}$

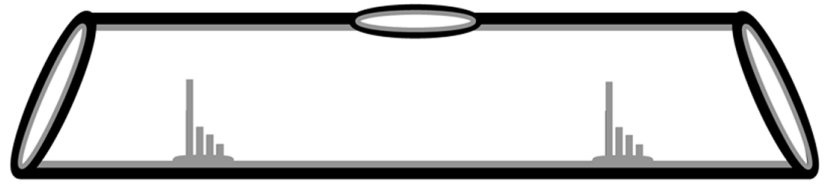

Figure 3: Neuromast-centered canal morphogenesis and fusion of adjacent canal segments. A) Stages of neuromast-centered canal morphogenesis (Stages I-IV): Stage I - neuromast found in general epithelium, Stage IIa - neuromast sinks into depression, Stage IIb - neuromast in groove with ossified canal walls forming on either side of neuromast, Stage III - neuromast enclosed by soft tissue canal roof, Stage IV - neuromast enclosed in canal and canal roof ossified over neuromast. Canal morphogenesis continues with the gradual fusion of adjacent canal segments. Adjacent canal segments grow toward one another (B) and make contact (C). The two segments fuse (D), leaving a pore between them (E), thus forming a continuous lateral line canal. Black = bone, Gray = general epithelium and neuromasts. (From Bird and Webb, 2014). 


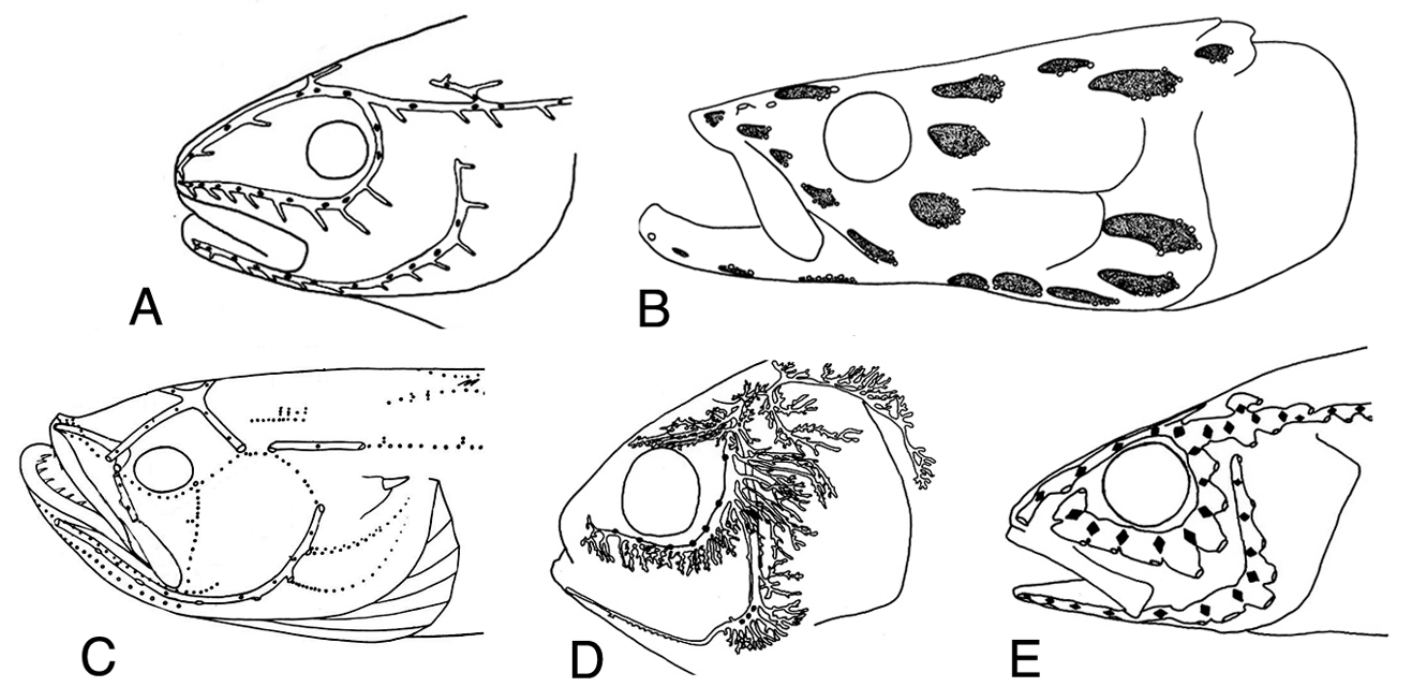

Figure 4: Five cranial lateral line canal morphologies found among fishes. A) Narrow canals, B) Narrow canals with widened tubules, C) Reduced canals, D) Branched canals, and E) Widened canals. (From Webb, 2014a). 


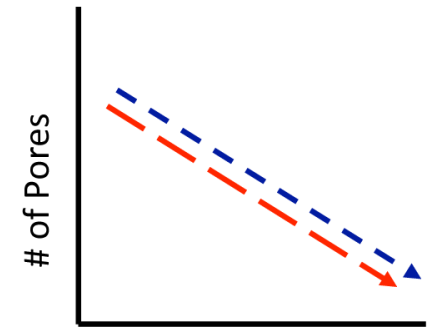

1 Fish size $(\mathrm{mm})$

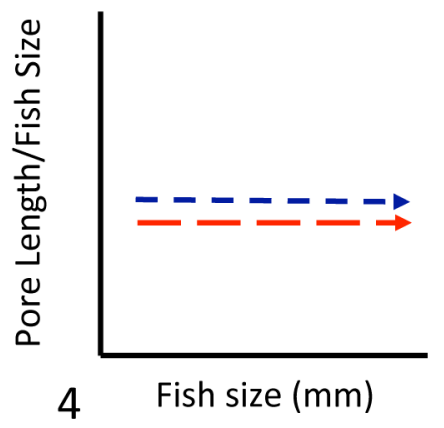

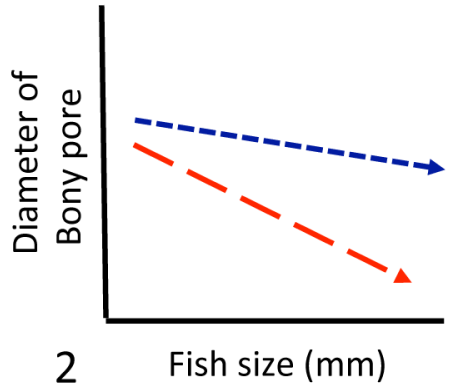

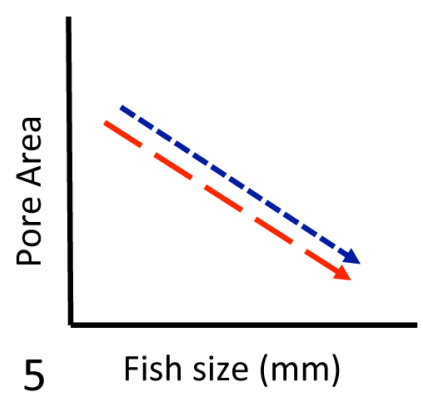

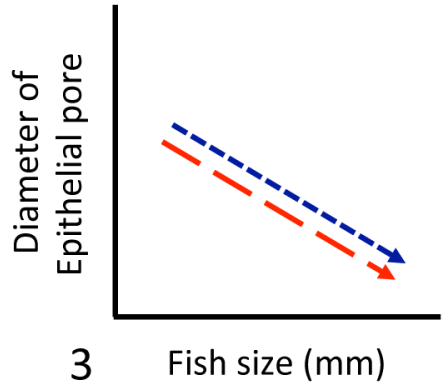

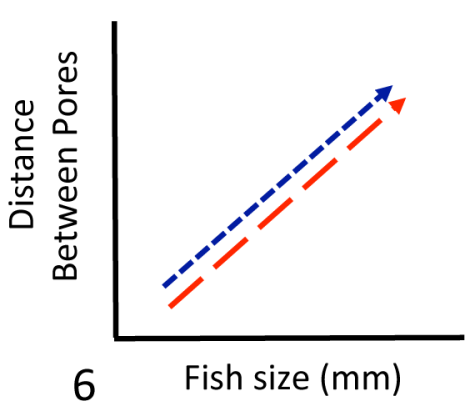

Figure 5: Graphical representation of six hypotheses. Aulonocara is represented by short, blue dashed lines. Tramitichromis represented by long, red dashed lines. See text for additional explanation. 


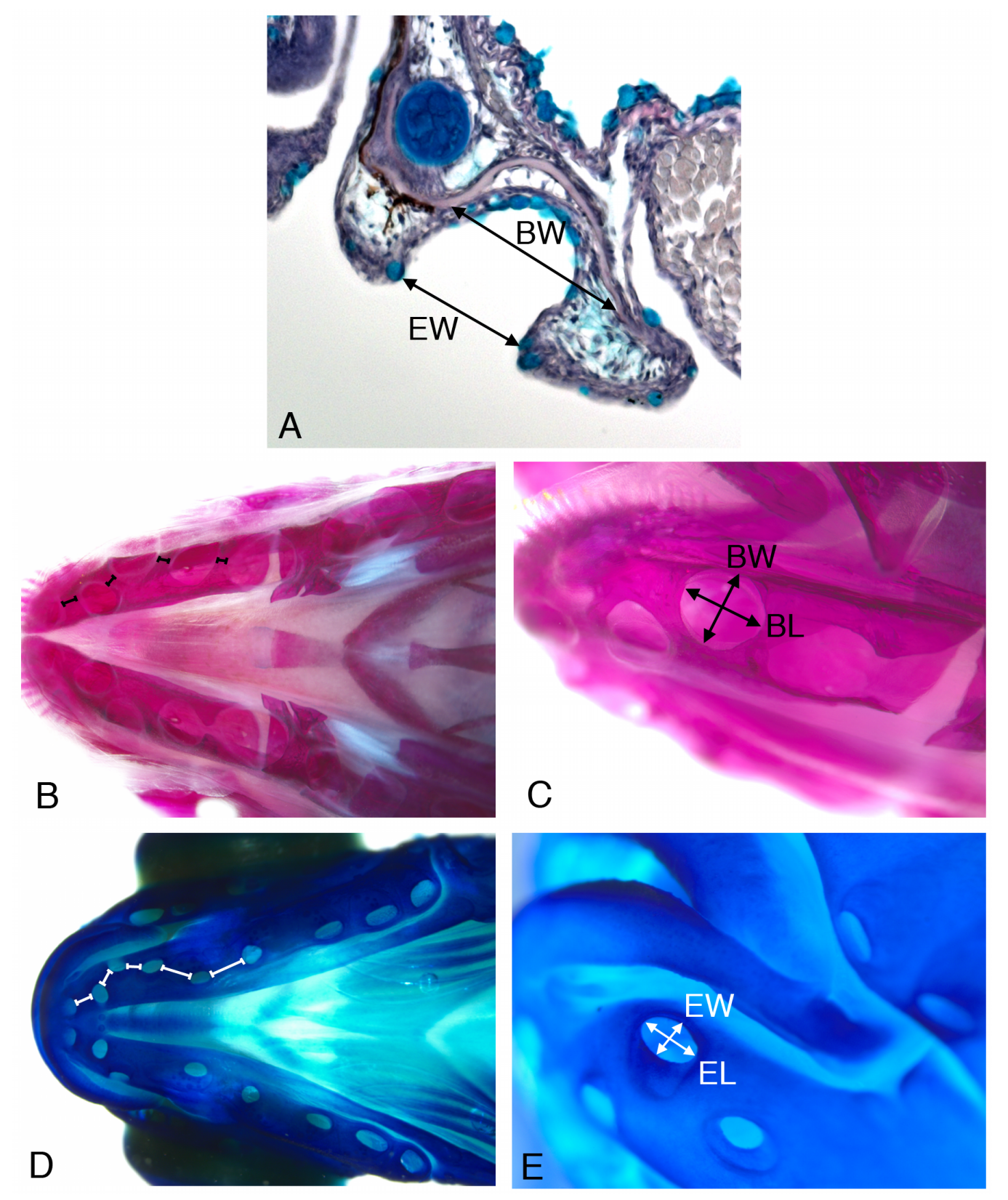

Figure 6: Definition of measurements taken for quantitative analysis of the ontogeny of bony and epithelial pores in the MD canal (of Aulonocara, as an example). A) Histological section showing how bony pore width (BW) and epithelial pore width (EW) were measured. B) Cleared and stained MD canals in ventral view (rostral to left) showing how distance between bony pores was measured. C) Cleared and stained MD (left side, rostral to left) showing how bony pore width (BW) and bony pore length (BL) were measured. D) Methylene blue stained MD canals in ventral view (rostral to left) showing how distance between epithelial pores was measured. E) Methylene blue stained MD (left side, rostral to left) showing how epithelial pore width (EW) and length (EL) were measured. All digital measurements were in micrometers. 


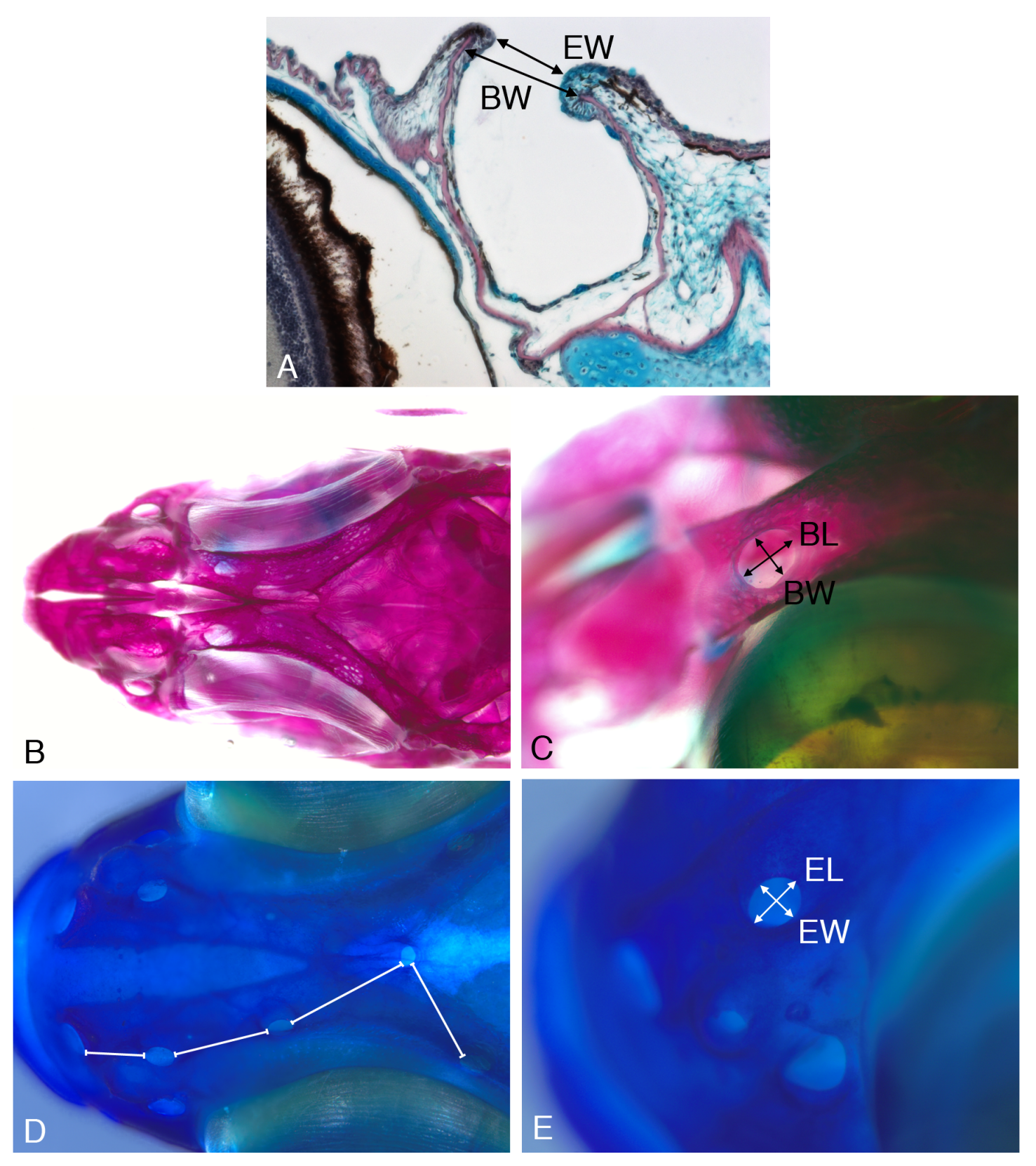

Figure 7: Definition of measurements taken for quantitative analysis of the ontogeny of bony and epithelial pores in the SO canal (of Aulonocara, as an example). A) Histological section showing how bony pore width (BW) and epithelial pore width (EW) were measured. B) Cleared and stained SO canals in ventral view (rostral to left) showing how distance between bony pores was measured. C) Cleared and stained SO (left side, rostral to left) showing how bony pore width (BW) and bony pore length (BL) were measured. D) Methylene blue stained SO canals in ventral view (rostral to left) showing how distance between epithelial pores was measured. E) Methylene blue stained SO (left side, rostral to left) showing how epithelial pore width (EW) and length (EL) were measured. All digital measurements were in micrometers. 

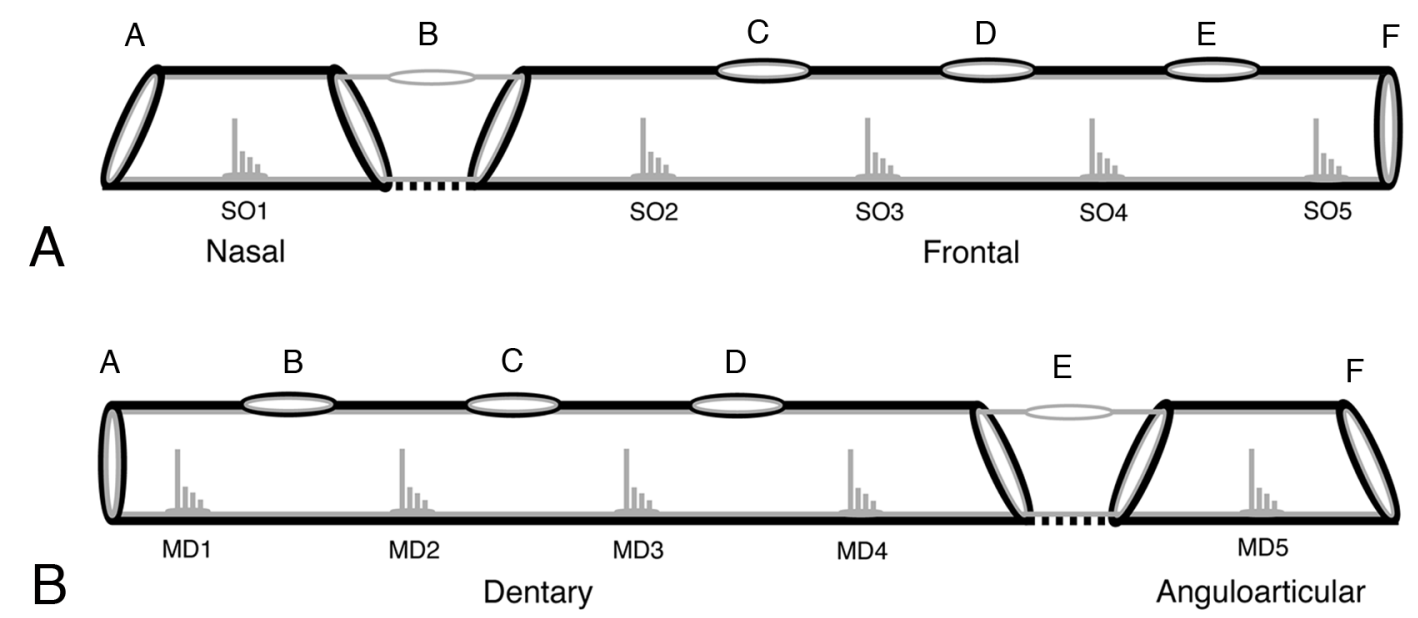

Figure 8: Configuration of the A) supraorbital (SO) canal in the nasal and frontal bones, and the B) mandibular (MD) canal in the dentary and anguloarticular bones, indicating the location of the canal neuromasts (SO1-5, MD1-5) and the canal pores located between neuromasts (SO A-F, MD A-F). From Bird and Webb, 2014. 


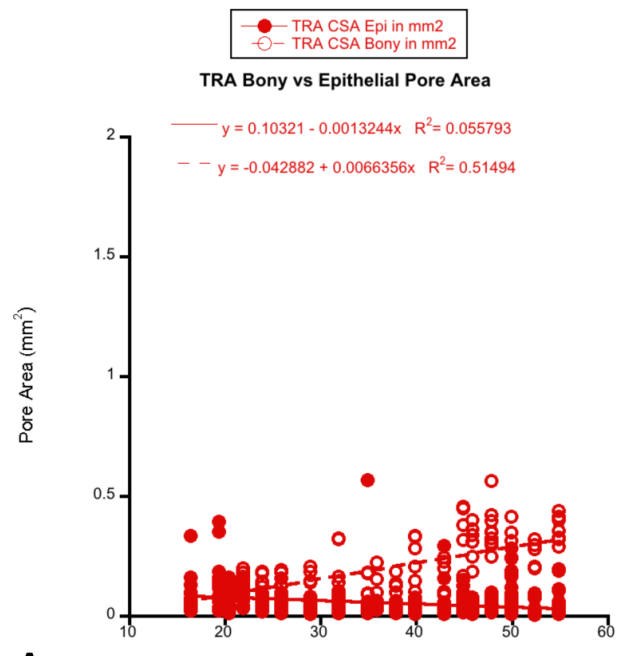

A

Fish Size (mm SL)

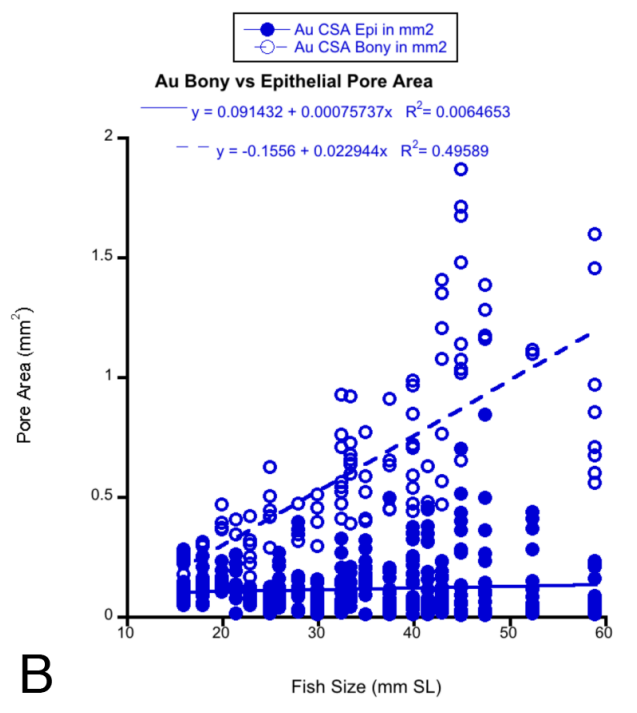

Figure 9: Comparison of the ontogeny of bony and epithelial pore area $\left(\mathrm{mm}^{2}\right.$, converted from $\mu \mathrm{m}^{2}$ as used in other statistical analyses, for illustration purposes) in larger juveniles and adults (16.5-59 mm SL) in A) Tramitichromis and B) Aulonocara. Note that the epithelial pores are close in size to the bony pores in Tramitichromis, but that the epithelial pores are much smaller than the bony pores in Aulonocara, especially in the largest individuals. 

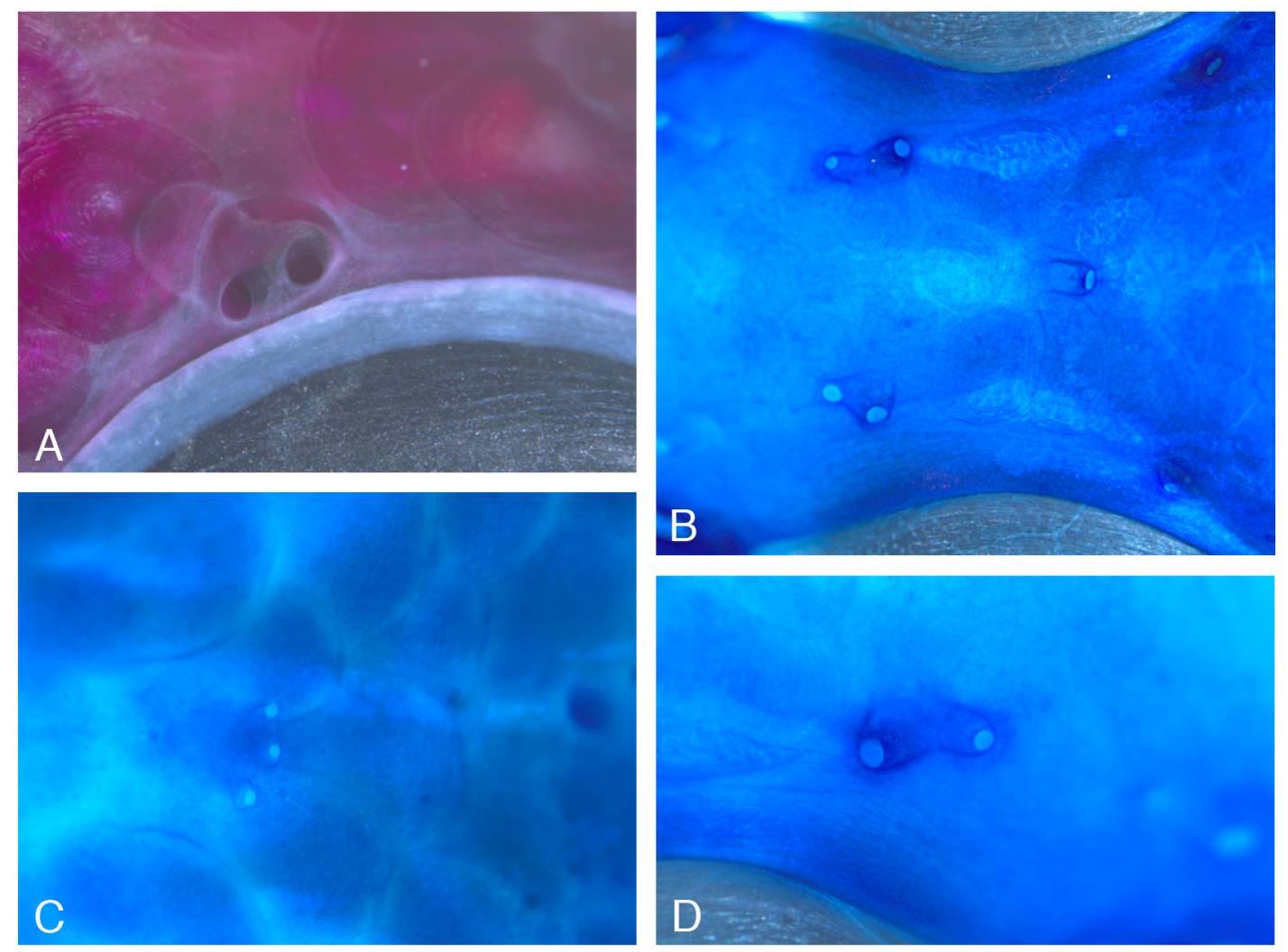

Figure 10: Proliferation of epithelial pores in the supraorbital canal (SO) in Aulonocara (A,B, and D) and Tramitichromis (C) . A) Two epithelial pores overlying the one bony pore (pore C) of the SO canal (rostral to left) in a cleared and stained Tramitichromis.

B) Dorsal view (rostral to left) showing two branched epithelial pores associated with one bony pore, C) Branching resulting in three epithelial pores associated with the common pore (pore D). D) Branching resulting in two epithelial pores overlying a single bony pore. Specimens range in size from 40-43 mm SL. 

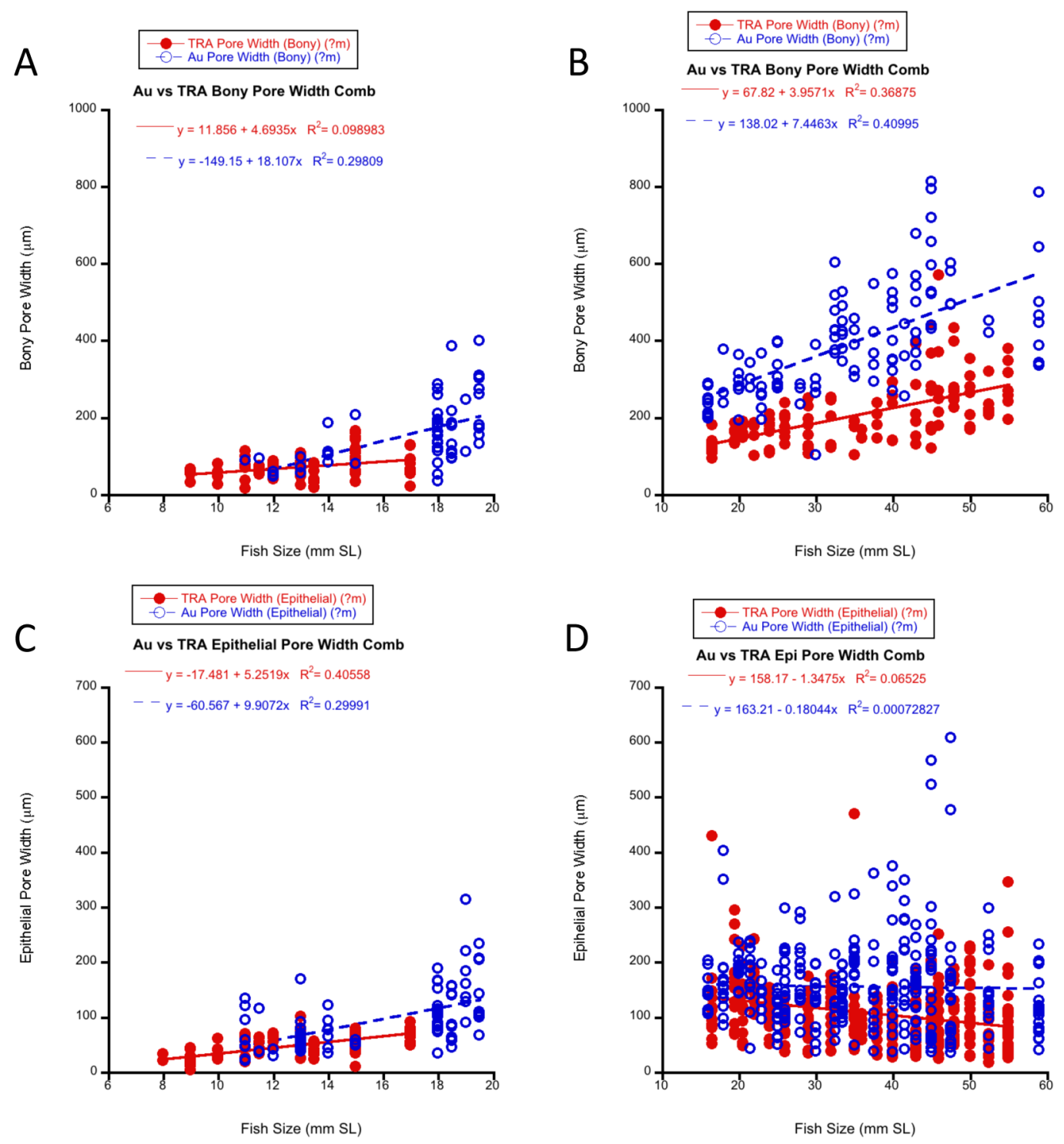

Figure 11: Comparison of Tramitichromis and Aulonocara with respect to bony pore width (A larvae and small juveniles, $\mathrm{B}$ - larger juveniles and adults) and epithelial pore width (C - larvae and small juveniles, $\mathrm{D}$ - larger juveniles and adults) using data from $\mathrm{SO}$ and MD canals combined. The data plotted are the non-transformed values. See Table 2, 3 and text for statistical analyses using transformed data where appropriate. 


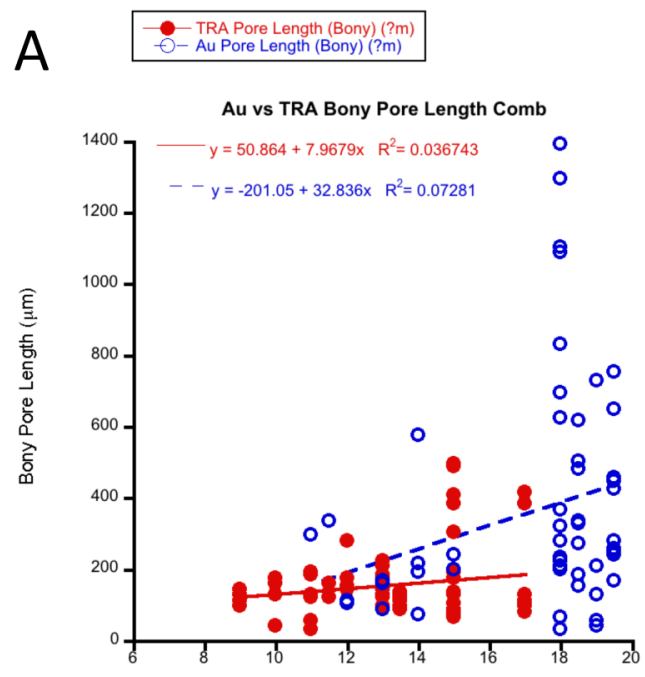

Fish Size $(\mathrm{mm} \mathrm{SL})$

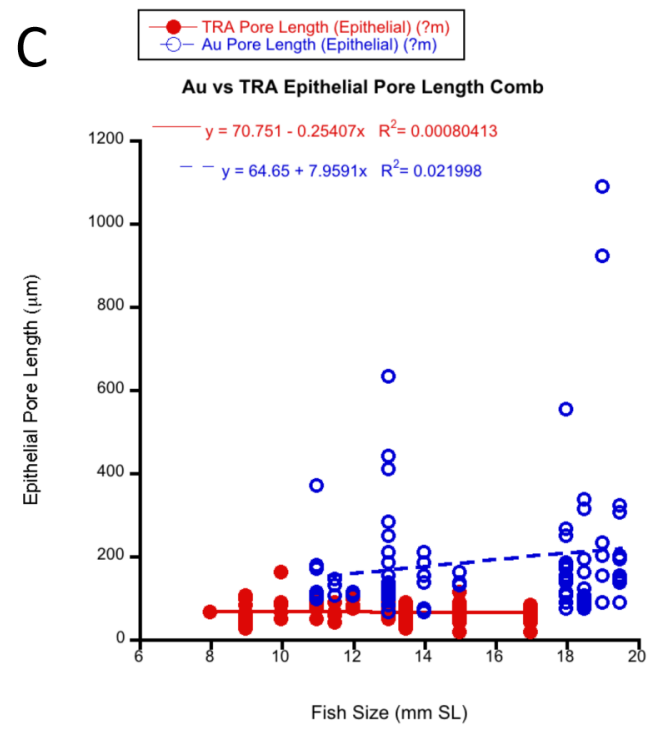

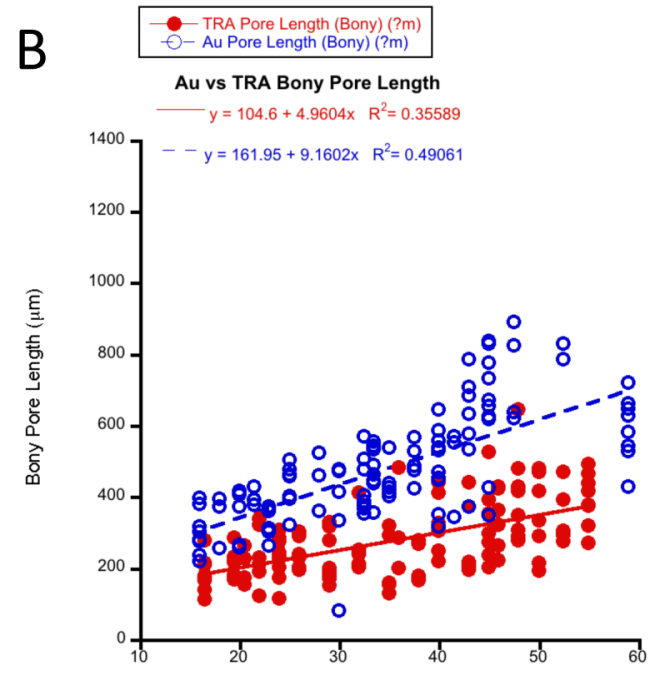

Fish Size (mm SL)

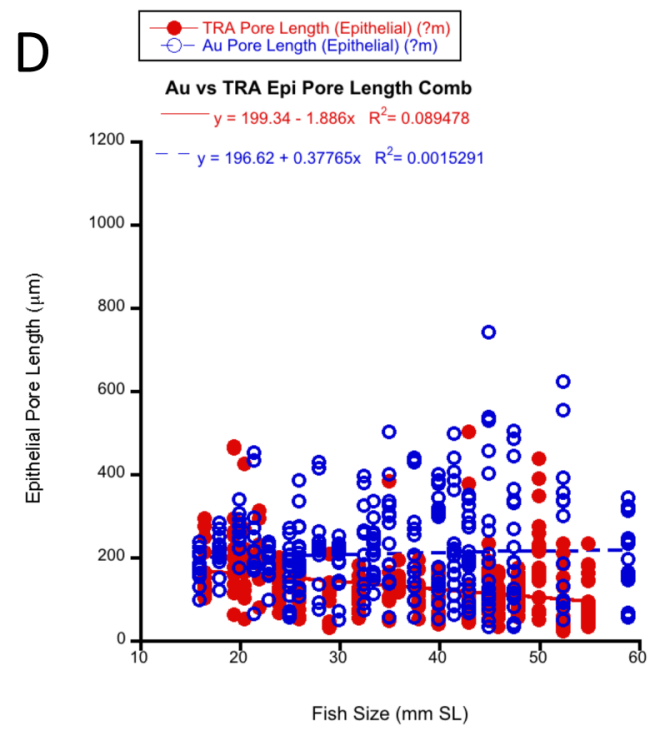

Figure 12: Comparison of Tramitichromis and Aulonocara with respect to bony pore length (A larvae and small juveniles (8-19.5 mm SL, B - larger juveniles and adults, 16-59 mm SL) and epithelial pore length (C - larvae and small juveniles, $\mathrm{D}$ - larger juveniles and adults) using data from SO and MD canals combined. The data plotted are the non-transformed values. See Table 2, 3 and text for statistical analyses using transformed data where appropriate. 

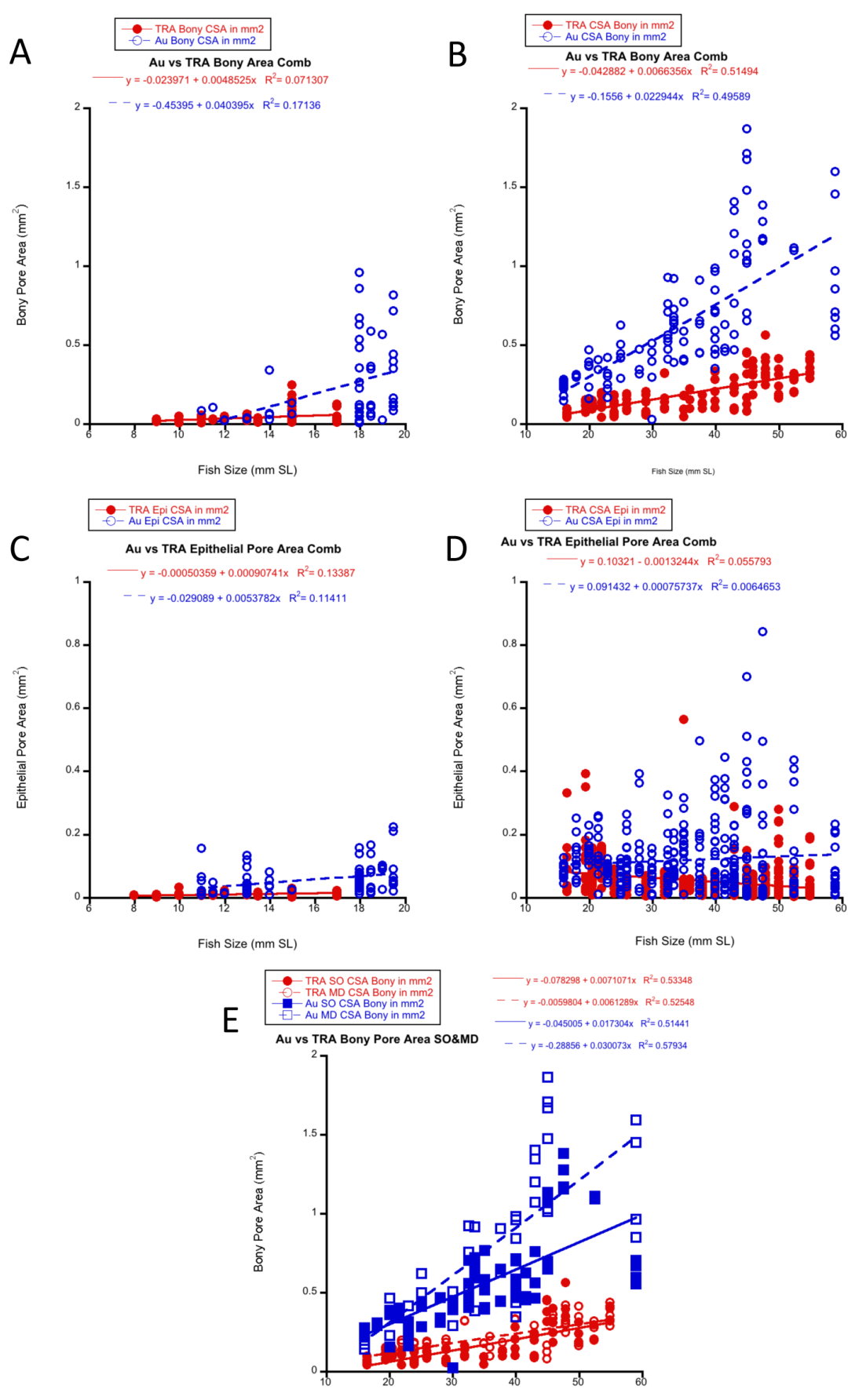

Fish Size (mm SL)

Figure 13: Comparison of Tramitichromis and Aulonocara with respect to pore area. A) Bony pore area (data from $\mathrm{SO}+\mathrm{MD}$ ) of larvae and small juveniles (8-19.5 mm SL). B) Bony pore area (SO+ MD) of larger juveniles and adults (16-59 mm SL). C) Epithelial pore area (SO+MD) of larvae and small juveniles. D) Epithelial pore area (SO+MD) of larger juveniles and adults. E) Bony pore area (canals split out, SO\&MD) in larger juveniles and adults. The data plotted are the non-transformed values. See Table 2, 3 and text for statistical analyses using transformed data where appropriate. 

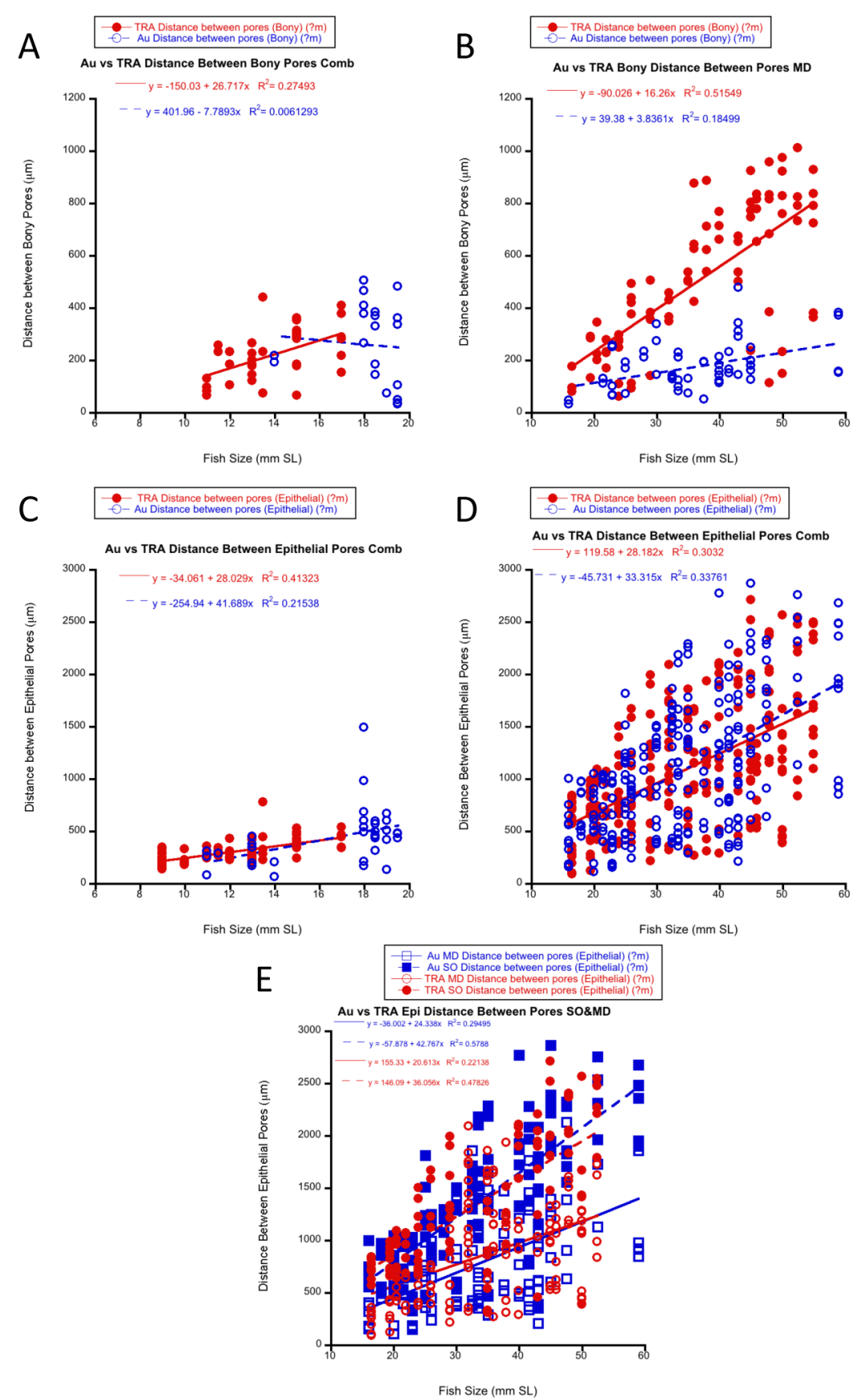

Figure 14: Comparison of distance between bony and epithelial pores in Tramitichromis and Aulonocara. A) Distance between bony pores (SO+MD) of larvae and small juveniles between species. B) Distance between bony pores (MD) of larger juveniles and adults between species. C) Distance between epithelial pores (SO+MD) of larvae and small juveniles between species. D) Distance between epithelial pores (SO+MD) of larger juveniles and adults between species. E) Distance between epithelial pores (canals split out, SO\&MD) in larger juveniles and adults between species. See text for statistical analysis. 


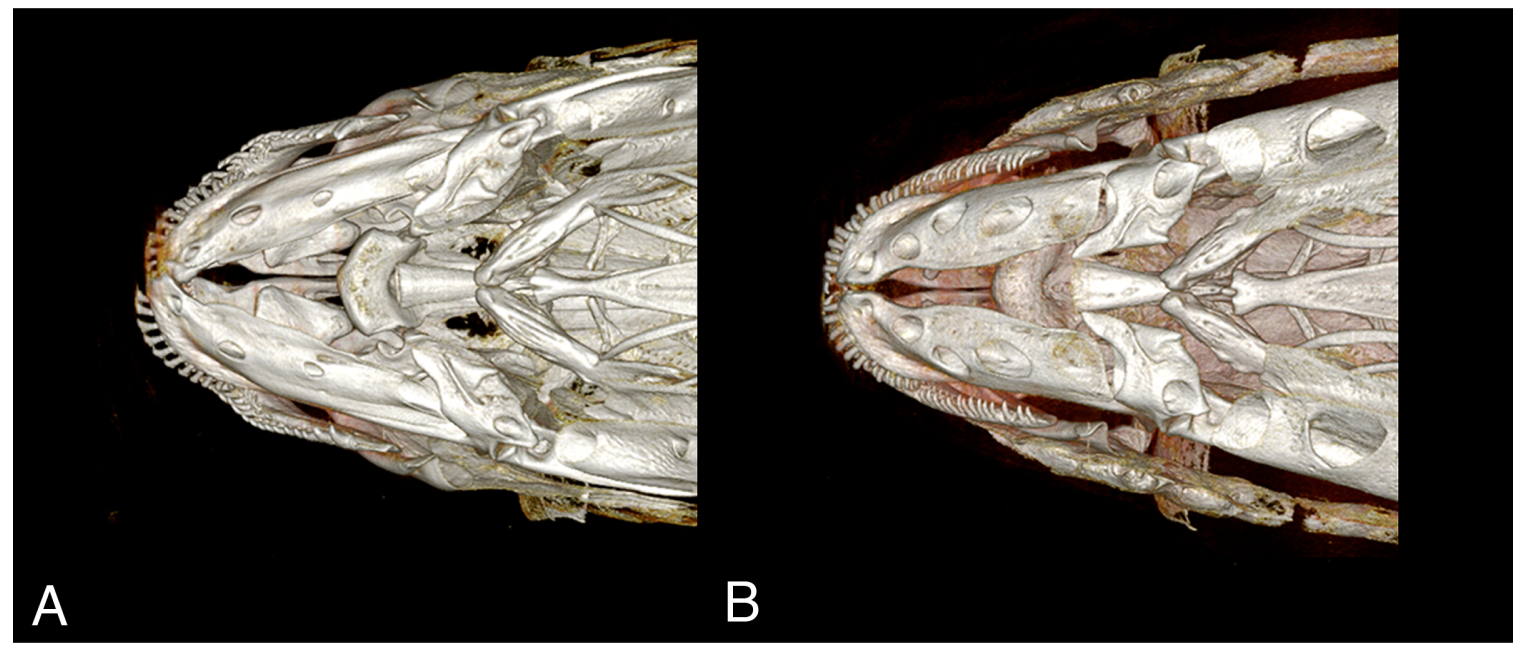

Figure 15: CT reconstructions of the mandibular canal in (A) Tramitichromis and (B) Aulonocara. Tramitichromis, adult $79 \mathrm{~mm}$ SL. Aulonocara, adult $78 \mathrm{~mm}$ SL. (From Bird and Webb, 2014) 
Aulonocara

A

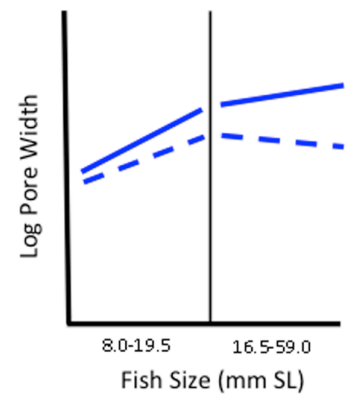

B

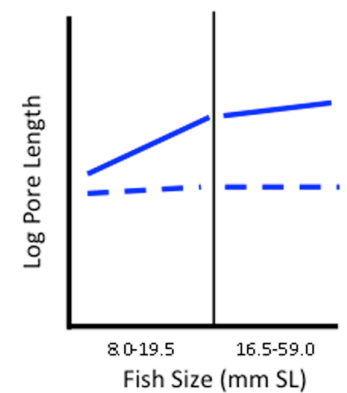

C

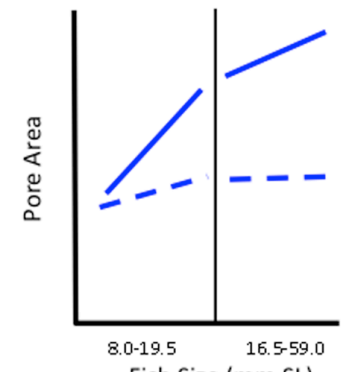

D

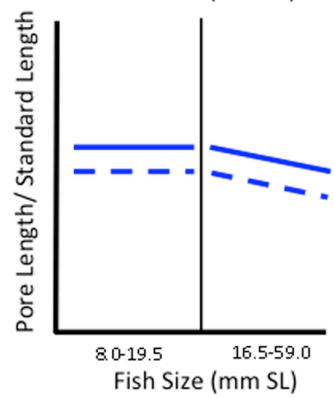

Tramitichromis

$\mathrm{E}$

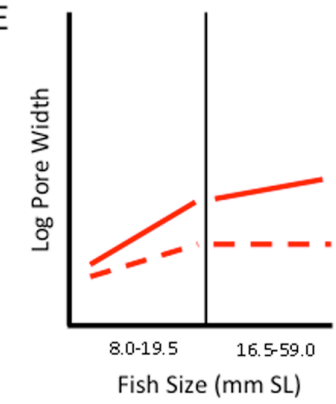

$\mathrm{F}$

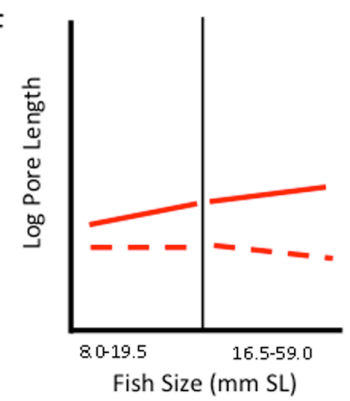

G
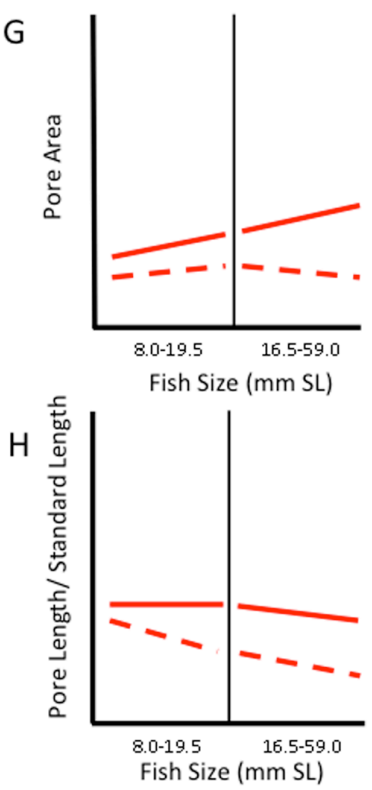

Figure 16: Schematic representation of overall statistical trends in four different morphological parameters (SO and MD data combined; transformed in those cases where data were not normally distributed, as in statistical analysis in test) in larvae and juveniles of Aulonocara and Tramitichromis. A, E) Trends in pore length. B, F) Trends in pore width. C, G) Trends in pore area. D, H) Trends in the ratio of pore length/SL. The vertical line in each graph distinguishes data for late-stage larvae and small juveniles vs. larger juveniles, which were analyzed using histology versus cleared and stained and methylene blue stained specimens, respectively (see text for additional explanation). Solid lines $=$ bony pores, dashed lines $=$ epithelial pores. 


\section{BIBILIOGRAPHY}

Becker E.A. 2013. The distribution and ontogeny of neuromast receptor organs and a comparison of methods for chemical ablation of the lateral line system in two cichlid fishes. MS Thesis. University of Rhode Island, $78 \mathrm{pp}$.

Bird, N.C., and Webb, J.F. 2014. Heterochrony and modularity in the functional evolution of the lateral line system. BMC - EvoDevo, 5:21. doi:10.1186/2041-9139-521.

Bleckmann, H and Zelick, R. 2009. Lateral line system in fish. Integrative Zoology. 4: $13: 25$.

Coombs, S., Braun, C.B., and Donovan, B. 2001. The orienting response of Lake Michigan mottled sculpin is mediated by canal neuromasts. Journal of Experimental Biology. 204: 337-348.

Coombs, S., Janssen, J., and Webb, J.F. 1988. Diversity of lateral line systems: evolutionary and functional considerations. In: Sensory Biology of Aquatic Animals (Atema, J., Fay, R. R., Popper, A. N., and Tavolga W.N., eds). NY: Springer-Verlag. pp. 553-593.

Denton, E. J., and Gray, J.A.B. 1988. Mechanical factors in the excitation of the lateral lines in fishes. In: Sensory Biology of Aquatic Animals (Atema, J., Fay, R. R., Popper, A. N., and Tavolga W.N., eds). Springer-Verlag, New York. Pp. 595-617.

Dijkgraaf, S. 1962. The functioning and significance of the lateral-line organs. Biological Reviews. 38: 51-105. 
Hall B.K. 1986. The role of movement and tissue interactions in the development and growth of bone and secondary cartilage in the clavicle of the embryonic chick. Journal of Embryology and Experimental Morphology. 93:133-152.

Janssen, J. 1997. Comparison of response distance to prey via the lateral line in the ruffe and yellow perch. Journal of Fish Biology. 51: 921-930.

Kalmijn, A. J.(1988). Hydrodynamic and acoustic field detection. In Sensory Biology of Aquatic Animals (eds J. Atema, R. R. Fay, A. N. Popper and W. N. Tavolga), pp. 83-130. New York: Springer-Verlag

Kanter, M. J. and Coombs, S. 2002. Rheotaxis and prey detection in uniform currents by Lake Michigan mottled sculpin (Cottus bairdi). Journal of Experimental Biology. 206: 59-70.

Kasumyan, A.O. 2003. The lateral line in fish: structure, function, and role in behavior. Journal of Ichthyology. 43(Suppl. 2): S175-S213.

Konings, A. 1990. Ad Koning's Book of Cichlids and Other Fishes of Lake Malawi. Neptune City, New Jersey: TFH Publications.

Lekander, B. 1949. The sensory line system and the canal bones in the head of some Ostariophysi. Acta Zoologica (Stockholm). 30: 1-131.

Marshall, N. J. 1996. The lateral line systems of three deep-sea fish. Journal of Fish Biology. 49(supplemental): 239-258.

Mogdans, J., and Bleckmann, H. 2012. Coping with flow: behavior, neurophysiology and modeling of the fish lateral line system. Biological Cybernetics. 106: 627-642.

Montgomery, J., Baker, C., and Carton, A. 1997. The lateral line can mediate rheotaxis in fish. Nature. 389: 960-963. 
Montgomery, J., and Coombs, S.(1998). Peripheral encoding of moving sources by the lateral line system of a sit-and-wait predator. J. Exp. Biol. 201:91-102.

Peters, H.M: Anatomie und entwicklungsgeschichte des lateralissystems von Tilapia (Pisces, Cichlidae). Z MorphTiere. 1973, 74:89-161.

Potthoff, T., 1984. Clearing and staining techniques. In: Ontogeny and Systematics of Fishes, Moser, H.G. (Ed.). Special Publication-American Society of Ichthyologists and Herpetologists, vol. 1. Allen Press, Lawrence, KS, USA, pp. $35-37$.

Satou, M., Takeuchi, H.A., Tanabe, M., Kitamura, A., Okumato, N., Iwata, M., and Nishii, J. 1994. Behavioral and electrophysiological evidence that the lateral line is involved in the inter-sexual vibrational communication of the hime salmon (landlocked red salmon, Oncorhynchus nerka). Journal of Comparative Physiology. A 174: 539-549.

Schwalbe, M.A.B., Bassett, D.K., and Webb, J.F. 2012. Feeding in the dark: Lateral line mediated feeding behavior in the peacock cichlid, Aulonocarastuartgranti. Journal of Experimental Biology. 215: 2060-2071.

Schwalbe, M.A.B., and Webb, J.F. 2014. Sensory basis for detection of benthic prey in two Lake Malawi cichlids.Zoology. 117:112-121.

Tarby, M.L. and Webb, J.F. 2003. Development of the supraorbital and mandibular lateral line canals in the cichlid, Archocentrus nigrofasciatus. Journal of Morphology. 255: 44-57.

Webb, J. F. 1989a. Developmental constraints and evolution of the lateral line system in teleost fishes. In: The Mechanosensory Lateral Line - Neurobiology and 
Evolution (Coombs, S., Gorner, R., and Munz, H., eds). Springer-Verlag, New York. pp. 79-98.

Webb, J. F. 1989b. Gross morphology and evolution of the mechanosensory lateral-line system in teleost fishes. Brain, Behavior and Evolution. 33: 34-53.

Webb J.F., Northcutt R.G. (1997) Morphology and distribution of pit organs and canal neuromasts in non-teleost bony fishes. Brain Behavior and Evolution. 50:139-151

Webb, J.F., and Shirey, J.E. 2003. Post-embryonic development of the lateral line canals and neuromasts in the zebrafish. Developmental Dynamics. 228: 370-385.

Webb J.F. 2014a.Morphological diversity, development, and evolution of the mechanosensory lateral line system. In The Lateral Line System. Edited by Bleckmann H, Coombs S., Mogdans J. New York: Springer.pp. 17-72.

Webb J.F. 2014b. Lateral line morphology and development and implications for the functional ontogeny of flow sensing of fishes. In Flow Sensing in Air and Water Behavioural, Neural and Engineering Principles of Operation.Edited by Bleckmann H., Mogdans J, Coombs S. New York: Springer. pp. 247-270.

Webb J.F., Bird N.C., Carter L, Dickson J. 2014. Comparative development and evolution of two lateral line phenotypes in Lake Malawi cichlids. Journal of Morphology. 275: 678-692.

Windsor, S.P., and McHenry, M.J. 2009. The influence of viscous hydrodynamics on the fish lateral-line system. Integrative and Comparative Biology. 49: 691-701.

Windsor, S. P., Tan, D. and Montgomery, J.2008. Swimming kinematics and hydrodynamic imaging in the blind Mexican cave fish (Astyanax fasciatus). Journal of Experimental Biology. 211: 2950-2959. 